\title{
Las políticas económicas y sociales predominantes a nivel mundial y sus implicaciones científicas y tecnológicas
}

\section{Introducción}

Las políticas económicas y sociales predominantes a nivel mundial no son ajenas al proceso de globalización de la economía y, específicamente, a la regionalización a la que esta última da lugar. Este será el marco que servirá como horizonte para examinar dichas políticas y la forma en que dichas políticas integran la ciencia y la tecnología.

Antes de pasar a ello conviene resaltar un aspecto: las políticas económicas y sociales predominantes a nivel mundial son las que emanan de acuerdos y pactos internacionales o regionales, siendo los Estados firmantes de esos acuerdos y pactos responsables de su cumplimiento. En este sentido, existen en la actualidad cuatro grandes pactos regionales, en los cuales se han formulado una serie de políticas económicas y sociales a ser asumidas por los Estados:

a) El Tratado de Libre Comercio para América del Norte (TLCAN), que tiene por objetivo articular en un bloque económico a Estados Unidos, Canadá y México, y a la región centroamericana;

b) El MERCOSUR que tiene por finalidad integrar económicamente a los países sudamericanos;

c) La Unión Europea, cuyo fin es integrar política, social y económicamente a los países europeos; $y$

d) La Asociación de Naciones del Sudeste Asiático (ASEAN, por sus siglas en inglés), creada con el objetivo de potenciar un bloque económico formado por los países del sudeste de Asia. 


\section{Caracterización de las políticas económicas y sociales}

\subsection{El Tratado de Libre Comercio para América del Norte (TLCAN)'}

Firmado el 17 de diciembre de 1992 por Canadá, Estados Unidos y México, entró en vigor el 1 de enero de 1994. Lo novedoso en él es que pretende integrar a dos economías industrializadas a una en vías de industrialización; asimismo, "representa a largo plazo, para los tres países, mejores posibilidades de acceso a mercados e inversiones y contribuye a aumentar la cooperación interempresarial y las corrientes de información. Estos son factores determinantes, ya que el libre comercio se ha constituido en uno de los parámetros más importantes para evaluar la efectividad de los distintos gobiernos en el aspecto económico"2. El TLCAN es el mecanismo de integración diseñado por los tres estados firmantes para hacer frente no sólo a la globalización económica, sino también a los desafíos planteados por la Unión Europea y los países del sudeste de Asia. Una vez firmado el Tratado, los gobiernos de México, Canadá y Estados Unidos han asumido una serie de compromisos sociales y económicos que tienen que ser cumplidos tanto a nivel doméstico como a nivel de sus relaciones internacionales.

Por otra parte, se trata de un acuerdo cuyo alcance va más allá de los tres países que hasta ahora lo han suscrito: sus promotores pretenden extenderlo a Centro y Sur América, aunque, para ello, las naciones que conforman esas regiones deben cumplir ciertos requisitos económicos y sociales. En su conjunto, el objetivo del TLCAN es crear la zona de libre comercio más grande del mundo, abarcando a una población de 387 millones de personas, cuya producción es de más de 800 millones de dólares anuales en bienes y servicios. Entre las metas principales del Tratado están la eliminación de barreras al comercio - aranceles y cuotas - y la protección a la propiedad intelectual. Ambas cosas no pueden lograrse sin importantes cambios jurídicos, institucionales, políticos y culturales. Asimismo, contempla temas como el medio ambiente, las normas laborales y el respeto a los derechos humanos e incluye la cláusula de adhesión para otros países ${ }^{3}$. A continuación, haremos una presentación global del TLCAN ${ }^{4}$ :

- El Tratado es un acuerdo trilateral, cuya meta principal es eliminar las barreras opuestas al comercio y a la inversión en la "zona de libre comercio" formada por Estados Unidos, México y Canadás. A la par de ese objetivo, el TLCAN se propone lograr condiciones de "justa competencia" entre los tres países firmantes. Otro de sus propósitos es proteger los derechos de propiedad intelectual. El Tratado promueve un marco general de cooperación que realza los beneficios a ser obtenidos por cada una de las naciones participantes.

- El Tratado ha permitido eliminar las barreras no arancelarias al comercio agrícola entre Estados Unidos y México; los aranceles no eliminados inmediatamente lo serán en un plazo de 5-15 años y todas las disposiciones relacionadas con la agricultura serán totalmente implementadas antes del año 
2008. Asimismo, para las industrias sensibles la importación, el TLCAN prevé ciertos periodos más largos de transición, así como salvaguardas especiales para permitir un ajuste ordenado del libre comercio con Méxicon.

- El Tratado aspira a fundarse en principios de "transparencia", "tratamiento nacional" y "nación más favorecida". La idea es que a partir de esos principios se facilite el movimiento de bienes y servicios a través de las fronteras, se garantice el cumplimiento de los derechos de propiedad intelectual, se adopten los procedimientos para la aplicación e implementación del Tratado y se establezca una regla de interpretación del TLCAN a la luz de sus objetivos y las normas del derecho internacional.

- Las disposiciones del Tratado de Libre Comercio entre Estados Unidos y Canadá relacionadas con la agricultura comenzaron a aplicarse en 1989 y fueron incorporadas al TLCAN. Según las normas aceptadas, todos los aranceles que afectan el comercio agrícola entre ambos países - con excepción de algunos bienes cubiertos por cuotas arancelarias - quedan eliminados a partir del 1 de enero de 1998. Es importante hacer notar que Canadá y México son, respectivamente, el tercero y cuarto mercados de exportación más grandes para los productos agrícolas estadounidenses, sólo superados por Japón y la Unión Europea.

- El TLCAN busca mejorar los incentivos de compra dentro de la región norteamericana, a la vez que pretende garantizar que los productos regionales recibirán los beneficios de todas las preferencias arancelarias nuevas. Los bienes que no se originan en ninguno los tres países deben transformarse o procesarse en forma significativa en uno de ellos antes de exportarse a cualquiera de los otros dos bajo los derechos arancelarios más favorables. Además, las normas de origen del TLCAN para productos agrícolas tiene como propósito impedir que México se convierta en plataforma de exportación de productos procesados a base de insumos subvencionados procedentes de países no firmantes del Tratado. Hay normas de origen particularmente fuertes para los artículos sensibles a la importación de Estados Unidos, como los cítricos y los productos lácteos.

- Los firmantes del TLCAN -miembros del Acuerdo General sobre Aranceles y Comercio (GATT) - han convenido en que las cláusulas de aquél prevalecerán en caso de conflicto con obligaciones mutuas contraídas anteriormente bajo el GATT. El TLCAN acepta la vigencia del GATT para regular el comercio entre sus miembros, con lo cual se incorpora la obligación de tratamiento nacional básico del GATT. Lo que ello significa es que, una vez importadas las mercaderías al país miembro, éstas no estarán sujetas a discriminación alguna.

- El TLCAN plantea disposiciones especiales de salvaguarda, relacionadas con la agricultura; su objetivo es ofrecer protección contra una marcada eleva- 
ción de las importaciones. Estas disposiciones permiten la entrada sólo de una cantidad determinada de productos con los aranceles bajos o preferenciales del Tratado y contemplan la aplicación de derechos aduaneros más altos cuando las importaciones rebasan el nivel especificado.

- El TLCAN prevé el establecimiento de un Comité Asesor trilateral capaz de ofrecer recomendaciones a los tres gobiernos para resolver disputas comerciales privadas que surjan en las transacciones de productos agrícolas. El objetivo es lograr una resolución pronta y efectiva de tales disputas, con especial atención a los artículos perecederos. El Comité está compuesto por representantes del sector privado y del sector gubernamental; además permite que cualquier país o grupo de países trate de incorporarse al TLCAN, en los términos y condiciones establecidos por la Comisión de Libre Comercio según los procedimientos nacionales de aprobación en cada país. Todo país puede declarar que el Tratado no se aplicará entre ese país y cualquier solicitante. El Tratado prevé que la Comisión, que opera según la regla del consenso, establecerá los términos y condiciones de aceptación de cualquier solicitante ${ }^{7}$.

\subsubsection{Políticas económicas}

\subsubsection{Marco general.}

El TLCAN establece una serie de medidas de política económica, siendo el objetivo de las mismas la "promoción del empleo y el crecimiento económico mediante la expansión del libre comercio y de las oportunidades de inversión en la zona de libre comercio" . A la par de ello, el Tratado busca promover "la competitividad internacional de las empresas mexicanas, canadienses y estadounidenses, en forma congruente con la protección del medio ambiente", el desarrollo sostenible y la protección de los derechos laborales". A continuación presentamos las medidas de política económica más relevantes.

\subsubsection{Medidas de política económica.}

\section{Apertura comercial.}

La apertura comercial, entonces, es el eje fundamental de las medidas de política económica propuestas por el Tratado, las cuales se derivan de sus objetivos básicos: elimiṇar barreras al comercio, promover las condiciones para una competencia justa, incrementar las oportunidades de inversión, proteger los derechos de propiedad intelectual, fomentar la cooperación trilateral, regional y multilateral. Precisamente, esos objetivos se lograrán mediante el cumplimiento de los principios y reglas del Tratado"'.

Las medidas de política económica apuntan a promover el comercio de bienes (textiles y prendas de vestir, productos automotores, energía y petroquímica 
básica y agricultura), para lo cual se han diseñado disposiciones en las siguientes áreas: trato nacional, acceso a mercados, eliminación de aranceles, restricciones a las importaciones y las exportaciones, devolución de aranceles, derechos de trámite aduanero, exención de aranceles, impuestos a la exportación, otras medidas relacionadas con la exportación, libre importación temporal de bienes, mercado del país de origen y bebidas alcohólicas-productos distintivos" .

\section{Desgravación arancelaria.}

Siendo la apertura comercial el principal objetivo económico del TLCAN, una buena parte de sus cláusulas tienen como propósito promover la desgravación arancelaria. Las medidas de reducción de aranceles se aplican a la mayoría del comercio, aunque existen restricciones, con periodos de transición especiales para la agricultura, los textiles y la industria automotriz. Gran parte de la reducción arancelaria se llevará a cabo en un plazo de 10 años, que se ampliará a 15 para algunos rubros. Se ha establecido un calendario de desgravación arancelaria a partir de los aranceles vigentes en julio de 1991 con el propósilo de llegar, al final del periodo de transición, a un comercio sin aranceles entre los tres países en el año 2010. En el caso de México, la desgravación ha sido más gradual, dado su menor nivel de desarrollo'2.

\section{Protección del mercado interno.}

Otro bloque de políticas económicas está encaminado a proteger el mercado interno respecto de países que utilizan práctica de comercio "desleal". Este se pretende corregir mediante leyes de comercio, entre las cuales destacan las disposiciones antidumping. El Tratado establece la creación de "tribunales arbitrales independientes", de integración binacional, "para que revisen las resoluciones definitivas en materia de antidumping y cuotas compensatorias que hayan dictado las autoridades competentes de los países signatarios. Cada país miembro llevará a cabo las reformas necesarias para asegurar la revisión efectiva por parte de esos tribunales arbitrales"13.

\section{Políticas relacionadas con la competencia.}

Para el fomento de la competencia, el Tratado adoptará o mantendrá medidas en contra de prácticas comerciales no competitivas; los monopolios y las empresas del Estado - para lo cual el Tratado exige que los gobiernos actúen en forma congruente con las obligaciones del país cuando ejerzan una función reglamentaria; además cada pais deberá asegurarse de que los monopolios no se valgan de su posición para involucrarse en prácticas contrarias a la competencia en mercados no monopólicos en su territorio ${ }^{14}$. 


\section{Medio ambiente.}

Un último bloque de disposiciones relacionadas con la economía tiene que ver con la protección del medio ambiente. Los tres países firmantes del Tratado se han comprometido a proteger el medio ambiente, así como impulsar el desarrollo sostenible. Los siguientes puntos recogen ese compromiso: i) Las obligaciones comerciales de los tres países derivadas de convenios internacionales determinados sobre especies en vías de extinción, sustancias que dañan la capa de ozono y deshechos peligrosos prevalecerán sobre las disposiciones del Tratado, sujeto al requisito de minimizar la compatibilidad de estos convenios con el TLCAN; ii) En el Tratado se confirma el derecho de cada país a determinar la protección que considere adecuada para el ambiente y para la vida o salud humana, animal o vegetal; iii) El Tratado establece claramente que, para asegurar el nivel de protección adecuado, cada país podrá adoptar y mantener normas sanitarias y fitosanitarias, incluyendo algunas que pudieran ser más estrictas que las internacionales; los tres países trabajarán conjuntamente por mejorar el nivel de protección del ambiente y de la vida y salud humana, animal y vegetal; y iv) Ningún país miembro deberá disminuir el nivel de protección de sus normas de salud, seguridad o ambiente, con el propósito de atraer inversión ${ }^{15}$.

\subsubsection{Políticas sociales}

\subsubsection{Marco general.}

Las políticas sociales planteadas en el TLCAN son un complemento de las políticas económicas. En este sentido, en el Tratado se abordan dos bloques de políticas sociales relacionadas con la apertura comercial y el establecimiento de una zona de libre comercio. Estas políticas contemplan la salud, la seguridad laboral y los derechos de propiedad intelectual.

\subsubsection{Medidas de política social.}

\section{Salud.}

El primer conjunto de políticas sociales se ubica en el apartado de "Medidas sanitarias y fitosanitarias". En esta parte, el Tratado establece los preceptos para el desarrollo, adopción y ejecución de medidas sanitarias y fitosanitarias que ayuden a proteger la vida y la salud humana, animal o vegetal, de los riesgos de enfermedades, plagas o sustancias contaminantes. En orden a implementar esos preceptos, el Tratado establece lo siguiente: i) Cada país tiene derecho a determinar el nivel de protección sanitaria y fitosanitaria que considere adecuado, pero tiene que hacerlo fundamentado en principios científicos y en una evaluación del riesgo, sólo en el grado necesario para el nivel de protección requerido por el país y sin imponer restricciones encubiertas, con esa protección, al comer- 
cio; ii) El Tratado alienta a los países a utilizar normas internacionales relevantes para el desarrollo de medidas sanitarias y fitosanitarias. Empero, deja abierta la posibilidad de que cada país pueda adoptar medidas más estrictas que las internacionales, apoyadas en investigaciones científicas, siempre y cuando sea necesario. En este mismo sentido, los países firmantes del Tratado promoverán el desarrollo y revisión de las normas sanitarias y fitosanitarias internacionales en el marco de las organizaciones de normalización internacionales y de América del Norte sobre la materia; iii) El Tratado establece que sus miembros deberán promover la equivalencia de las medidas sanitarias y fitosanitarias, sin reducir el nivel de protección de la vida o la salud humana, vegetal y animal determinado por cada país; iv) El TLCAN establece preceptos para la evaluación del riesgo que incluye aquellos para la evaluación de la probabilidad de entrada, radicación o propagación de plagas y enfermedades. Las medidas sanitarias y fitosanitarias se fundamentarán en una evaluación del riesgo contra la vida humana o la salud animal o vegetal, tomando en cuenta las técnicas de evaluación del riesgo desarrolladas por las organizaciones de normalización internacionales o de América del Norte sobre la materia; v) El Tratado establece reglas para la adaptación de medidas sanitarias y fitosanitarias a las condiciones regionales, en particular las relativas a zonas libres o de escasa prevalencia de plagas o enfermedades; vi) El Tratado dispone de reglas sobre los procedimientos para garantizar el cumplimiento de las medidas sanitarias y fitosanitarias, las cuales permiten la operación continua de los procedimientos internos de control, inspección y aprobación, con apego a los principios de trato nacional, oportunidad y transparencia en los procedimientos, incluidos los sistemas nacionales para la aprobación del uso de aditivos o para el establecimiento de tolerancias de contaminación en alimentos, bebidas y forrajes; vii) Los países firmantes del Tratado facilitarán la prestación de asistencia técnica relativa a medidas sanitarias y fitosanitarias, ya sea de manera directa o mediante las organizaciones de normalización pertinentes, internacionales o de América del Norte; viii) Un Comité de medidas sanitarias y fitosanitarias contribuirá a mejorar la seguridad de los alimentos y las condiciones sanitarias en la zona de libre comercio, a promover la armonización y equivalencia de las medidas sanitarias y fitosanitarias, y a facilitar la cooperación y las consultas técnicas, incluso las referentes a controversias en la materia ${ }^{\text {th }}$.

\section{Seguridad laboral.}

El segundo bloque 'de políticas sociales se ubica en la seguridad laboral, específicamente en el apartado de "normas lécnicas y de seguridad". El Tratado señala que, con base en el compromiso de los tres países para mejorar los niveles de salud y seguridad, y de proteger a los consumidores y al ambiente, los países firmantes buscarán hacer compatibles las normas relativas al autotransporte y a las operaciones ferroviarias, comprendiendo: i) Vehículos, incluidos equipos 
como llantas y frenos, peso y dimensiones, mantenimiento y reparación y niveles de emisión; ii) Pruebas no médicas y licencias para conductores de camiones; iii) Normas médicas para conductores de camiones; iv) Locomotoras y otro equipo ferroviario y normas para personal operativo relevantes en las operaciones transfronterizas; v) Normas relacionadas con el transporte de sustancias peligrosas; vi) Señalización en las carreteras y cumplimiento de los requisitos de seguridad en autotransporte; y vii) Cada uno de los países establecerá centros que brinden información sobre transporte terrestre, en cuestiones como autorizaciones para operar y requisitos de seguridad ${ }^{17}$.

\section{Propiedad intelectual.}

El tercer y último de bloque de políticas sociales se enmarca en el tema de la propiedad intelectual. Al respecto, el TLCAN establece obligaciones significativas relativas a la propiedad intelectual, que se fundamentan en el trabajo realizado por el GATT y los convenios internacionales más importantes sobre la materia. Cada país protegerá adecuada y efectivamente los derechos de propiedad intelectual con base en el principio de trato nacional y asegurará el cumplimiento efectivo de estos derechos, tanto en todo el país como en las fronteras. El Tratado define compromisos específicos sobre la protección de: i) Derechos de autor, incluyendo los fonogramas; ii) Patentes; iii) Marcas; iv) Derechos de los obstentores de vegetales; v) Diseños industriales; vi) Secretos industriales; vii) Circuitos integrados (semiconductores); y viii) Indicaciones geográficas.

Sobre los derechos de autor, el Tratado plantea las siguientes obligaciones para los países miembros: i) Proteger los programas de cómputo como obras literarias, y las bases de datos como compilaciones; ii) Conceder derechos de renta para los programas de cómputo y fonogramas; y iii) Estipular un plazo de protección de por lo menos 50 años para los fonogramas; iv) Proteger las marcas de servicios en igual medida que las de productos, las señales codificadas emitidas por satélites, en contra de su uso ilegal, los secretos industriales en general, así como la protección contra la divulgación por parte de las autoridades competentes de resultados presentados por las empresas relativos a la seguridad y eficacia de sus productos farmacéuticos o agroquímicos, los circuitos integrados tanto en sí mismos, como a los bienes que los incorporen, y las indicaciones geográficas, para proteger a los titulares de las marcas y evitar inducir al público a error.

Asimismo, el Tratado otorga protección a las invenciones, solicitando a cada país: i) Conceder patentes para productos y procesos en prácticamente todo tipo de inventos, incluidos los farmacéuticos y agroquímicos; ii) Eliminar cualquier régimen especial para categorías particulares de productos, cualquier disposición para la adquisición de los derechos de patentes, y cualquier discriminación en la disponibilidad y goce de los derechos de patentes que se otorguen localmente y en el extranjero; y iii) Brindar la oportunidad a los titulares de las patentes para 
que obtengan protección en los inventos relativos a productos farmacéuticos y agroquímicos que antes no podían ser patentados.

Por último, el TLCAN incluye obligaciones detalladas sobre: i) Los procedimientos judiciales para la puesta en práctica de los derechos de propiedad intelectual, incluidas las disposiciones relativas a daños, suspensión precautoria y, en general, a los aspectos de legalidad en los procedimientos; y ii) El cumplimiento de los derechos de propiedad intelectual en la frontera, incluidas las salvaguardias para prevenir el abuso ${ }^{18}$.

\subsection{Mercado Común del Sur (MERCOSUR)}

MERCOSUR, por su magnitud económica, es el cuarto bloque comercial del mundo ${ }^{19}$. Está integrado por cuatro países: Argentina, Brasil, Paraguay y Uruguay y se constituyó a partir del Tratado de Asunción, suscrito el 26 de marzo de 1991. La forma definitiva que adoptó el bloque surgió de los Protocolos de Ouro Preto acordados en diciembre de 1994. El 1o. de enero de 1995 nació una Unión Aduanera entre los cuatro países signatarios. Los dos principios básicos que rigen la Unión son:

a) El libre comercio, sin trabas arancelarias ni para-arancelarias entre los Estados miembros; $y$

b) Un arancel externo común frente a terceros paises.

Durante un período de transición que, para la mayoría de los productos, concluye en el año 2001, existen algunas excepciones a esos dos principios:

a) El llamado Régimen de Adecuación, por el cual los productos que cada país considera sensibles mantienen un cierto nivel de protección para el comercio recíproco, de modo de darles tiempo para adecuarse a la competencia regional e internacional; dichos productos son desgravados progresivamente hasta llegar al arancel 0 ; y

b) Excepciones al arancel externo común, establecidas por cada país para una lista limitada de productos. Los aranceles nacionales sobre esos productos convergen gradualmente, en forma lineal y automática, hasta llegar al arancel definitivo en el 2001.

Un aspecto relevante del acuerdo comercial es que los sectores automotriz y azucarero tendrán un régimen especial durante el período de transición. Asimismo, la protección global del MERCOSUR se situará entre un $14 \%$ y un $16 \%$, según los productos, una vez concluido el período de transición. El MERCOSUR se ubica dentro de lo que se denomina un regionalismo abierto, que se caracteriza por una Unión abierta a otros bloques y países, como lo muestran el Acuerdo Marco de Cooperación firmado con la Unión Europea en Madrid, el 15 de diciembre de 1995. Este Acuerdo establece el inicio de un proceso de negociacio- 
nes tendientes a liberalizar las relaciones comerciales entre ambos bloques. Es de hacer notar que el Acuerdo entre el MERCOSUR y la Unión Europea es el primero de este tipo en el mundo, pues nunca antes dos bloques regionales dieron señales de promover la convergencia de intereses para la creación de un área de libre comercio más amplia aún que la ya lograda con países vecinos.

A grandes rasgos, el MERCOSUR, como señala Aldo Ferrer, tiene como propósito fundamental lograr una "integración sustentable" que libere las fuerzas creadoras privadas y los mercados, al tiempo que eleva la calidad de vida y garantiza la preservación del ambiente, potenciando un "desarrollo sustentable" que resulta de la convergencia de las "fuerzas del mercado y la acción pública" ${ }^{20 .}$. "El desarrollo - dice Ferrer- sigue un proceso esencialmente endógeno y los Estados nacionales conservan la suficiente libertad de maniobra para influir en el desarrollo y la inserción internacional de los países y, consecuentemente, de la integración regional. La libertad de maniobra frente a las expectativas de los mercado y los operadores transnacionales descansa básicamente en la solidez de los equilibrios macroeconómicos, en la estabilidad de las reglas del juego y en los incentivos generados por la tasa de crecimiento"21.

De acuerdo con Isidoro Hodara, "la vocación del MERCOSUR no es, desde su origen y su propia denominación, agotar la experiencia de integración en la etapa de la unión aduanera. Hasta el presente el proceso de conformación del MERCOSUR se ha concentrado esencialmente en el comercio de bienes. No obstante, en el curso de los próximos tiempos habrá de hacer frente a temas como el comercio de servicios y factores de producción, la consideración de la política de competencia a adoptar, el eventual establecimiento de algunas políticas comunes y la coordinación de otras políticas, incluidas en alguna medida las macroeconómicas. Ello habrá de ocurrir pues se trata de puntos destacados en la agenda de la construcción de un mercado común, que es la modalidad de integración elegida por el MERCOSUR. Adicionalmente, en el caso de varios de estos temas se trata de puntos que serán presumiblemente incluidos en eventuales negociaciones tendientes a una zona de libre comercio hemisférica o a un acuerdo preferencial con la Unión Europea"z2.

Para finalizar con esta presentación general del MERCOSUR es pertinente traer a cuenta los preámbulos del Tratado para la constitución de un mercado común entre la República Argentina, la República federativa del Brasil, la República del Paraguay y la República Oriental del Uruguay, el documento fundacional del bloque comercial formado por esos cuatro países. El texto, entre otras cosas, dice lo siguiente: "la República Argentina, la República Federativa de Brasil, la República de Paraguay y la República Oriental de Uruguay, en adelante denominados "Estados Partes"; CONSIDERANDO que la ampliación de las actuales dimensiones de sus mercados nacionales, a través de la integración, constituye condición fundamental para acelerar sus procesos de desarrollo 
económico con justicia social; ENTENDIENDO que ese objetivo debe ser alcanzado mediante el más eficaz aprovechamiento de los recursos disponibles, la preservación del medio ambiente, el mejoramiento de las interconexiones físicas, la coordinación de las políticas macroeconómicas y la complementación de los diferentes sectores de la economía, con base en los principios de gradualidad, flexibilidad y equilibrio; TENIENDO en cuenta la evolución de los acontecimientos internacionales, en especial la consolidación de grandes espacios económicos y la importancia de lograr una adecuada inserción internacional para sus países; EXPRESANDO que este proceso de integración constituye una respuesta adecuada a tales acontecimientos; CONSCIENTES de que el presente Tratado debe ser considerado como un nuevo avance en el esfuerzo tendiente al desarrollo en forma progresiva de la integración de América Latina, conforme al objetivo del Tratado de Montevideo de 1980; CONVENCIDOS de la necesidad de promover el desarrollo científico y tecnológico de los Estados Partes y de modernizar sus economías para ampliar la oferta y la calidad de los bienes y servicios disponibles a fin de mejorar las condiciones de vida de sus habitantes; REAFIRMANDO su voluntad política de dejar establecidas las bases para una unión cada vez más estrecha entre sus pueblos, con la finalidad de alcanzar los objetivos arriba mencionados, ACUERDAN: constituir un Mercado Común, que deberá estar conformado al 31 de diciembre de 1994, el que se denominará "Mercado Común del Sur" (MERCOSUR)"?3.?.

\subsubsection{Políticas económicas}

\subsubsection{Marco general.}

El MERCOSUR tiene como propósito económico fundamental poner en marcha un Programa de Liberación Comercial, que consistirá en rebajas arancelarias progresivas, lineales y automáticas, acompañadas de la eliminación de restricciones no arancelarias o medidas de efectos equivalentes, así como de otras restricciones al comercio entre los Estados Partes, para llegar al 31 de diciembre de 1994 con arancel cero, sin restricciones no arancelarias sobre la totalidad del universo arancelario. Ello supone, asimismo, la coordinación de políticas macroeconómicas que se realizará gradualmente y en forma convergente con los programas de desgravación arancelaria y de eliminación de restricciones no arancelarias, así como la adopción de acuerdos sectoriales, con el fin de optimizar la utilización y movilidad de los factores de producción, alcanzar escalas operativas eficientes e incentivar la competitividad externa de los Estados parte ${ }^{24}$.

\subsubsection{Medidas de política económica}

Las políticas económicas contempladas en el MERCOSUR se pueden agrupar en los siguientes bloques: 
a) Un primer grupo de políticas económicas que apuntan a la libre circulación de bienes, servicios y factores productivos entre los paises, a través, entre otros, de la eliminación de los derechos aduaneros y restricciones no arancelarias a la circulación de mercaderías y de cualquier otra medida equivalente;

b) El segundo grupo apunta al establecimiento de un arancel externo común y la adopción de una política comercial común con relación a terceros Estados o agrupaciones de Estados y la coordinación de posiciones en foros económico-comerciales regionales $e$ intemacionales; $y$

c) El tercer grupo tiene que ver con la coordinación de políticas macroeconómicas y sectoriales entre los Estados Partes: de comercio exterior, agrícola, industrial, fiscal, monetaria, cambiaria y de capitales, de servicios, aduanera, de transportes y comunicaciones y otras que se acuerden, a fin de asegurar condiciones adecuadas de competencia entre los Estados Partes ${ }^{25}$.

Las políticas económicas señaladas son complementadas con otras dadas a conocer en el Acuerdo de alcance parcial de complementación económica, de 1991, que tiene como objeto facilitar la creación de las condiciones necesarias para el establecimiento del Mercado Común a constituirse de conformidad con el Tratado de Asunción de fecha 26 de marzo de 1991, cuyos principales instrumentos, durante el periodo de transición, son:

a) Un Programa de Liberación Comercial, que consistirá en rebajas arancelarias progresivas, lineales y automáticas, acompañadas de la eliminación de restricciones no arancelarias o medidas de efectos equivalentes, así como de otras restricciones al comercio entre los Estados Parte, para llegar al 31 de diciembre de 1994 con arancel 0 , sin restricciones no arancelarias sobre la totalidad de universo arancelario;

b) La coordinación de políticas macroeconómicas que se realizará gradualmente y en forma convergente con los programas de desgravación arancelaria y de eliminación de restricciones no arancelarias indicados en el literal anterior;

c) Un arancel externo común, que incentive la competitividad externa de los países signatarios; $y$

d) La adopción de acuerdos sectoriales, con el fin de optimizar la utilización y movilidad de los factores de producción y de alcanzar escalas operativas eficientes ${ }^{26}$.

\subsubsection{Políticas sociales}

\subsubsection{Marco general.}

El MERCOSUR enfatiza, en materia de políticas sociales, aquellas relacionadas con la educación de los ciudadanos de los países miembros. La educación, 
en sus diversos niveles, está llamada a convertirse en un pilar básico de la integración regional y el desarrollo económico de los países firmantes.

\subsubsection{Medidas de política social}

En materia educativa, las áreas de política que privilegia el MERCOSUR son las siguientes:

a) Renovación educativa. Incorporar la perspectiva regional a la cultura de las instituciones; formar agentes educativos teniendo en cuenta la mejora de la calidad del aprendizaje;

b) Apreciación educativa. Establecer parámetros regionales en la materia, a modo de facilitar el reconocimiento de estudios y la identificación de las áreas de excelencia;

c) Cooperación interuniversitaria. Fortalecer la actividad universitaria en la región, impulsando la generación de nuevos conocimientos y la formación de recursos humanos en el cuadro de la integración regional;

d) Sistema de información. Consolidar e integrar el sistema de información en educación de los países miembros, para colocar a disposición del público en general, vía INTERNET, datos sobre la educación en la región y sobre el sector educativo en el MERCOSUR;

e) Educación y trabajo. Definir las competencias básicas y de trabajo comunes a los países miembros; promover una mayor vinculación entre los sistemas de formación y el mundo del trabajo; y

f) Temas colaterales. Formar una conciencia favorable al proceso de integración cultural y social; estimular el desarrollo armónico e integral para la toma de conciencia sobre salud, nutrición y medio ambiente, comportamientos de connivencias pluralistas y participativas en la región ${ }^{27}$.

Según los gobiernos firmantes del MERCOSUR, la educación tiene que ser ubicada en el marco del proceso de globalización y regionalización por el que atraviesa el mundo contemporáneo. Este proceso está acompañado por el avance de la revolución científico-tecnológica, por la democratización creciente de la sociedad y por la constitución de bloques geo-culturales. En ese sentido, la promoción del desarrollo científico-tecnológico de los Estados integrantes es clave para asegurar las condiciones fundamentales de competitividad. Implementar un nuevo modelo de educáción hace necesario definir cambios en los estilos tradicionales de acción educativa, a fin de responder aquellas exigencias de un nuevo modelo de desarrollo, basado en la concreción de altos niveles de competitividad externa y justicia social, en un contexto democrático y participativo ${ }^{2 \mathrm{~B}}$.

Los elementos más importantes de la estrategia educativa diseñada por el MERCOSUR son los siguientes: 
a) Introducir una definición de la articulación de las estrategias de desarrollo de medio y largo plazo. Agilizar los procesos de planeamiento y gestión vinculados a los procesos de cambios en curso;

b) Fortalecer la eficacia en la gestión de los sistemas, en la búsqueda de recursos y de la efectividad en la transmisión de conocimientos y en la formación de habilidades y actitudes;

c) Mejorar la calidad de la educación en todos los niveles de enseñanza;

d) Oferta de las mismas oportunidades educativas a los integrantes de todos los sectores sociales;

e) Promover programas actualizados de formación y capacitación docente, tanto desde el punto de vista de los contenidos de los conocimientos específicos, como de las formas para su transmisión; y

f) Más allá de eso, es necesario el establecimiento de una nueva alianza entre el sector educativo y el sector productivo, mediante los procesos de reconversión competitiva que involucran a los países del área. Esto exige asegurar una apropiación generalizada y equitativa del conocimiento científico y tecnológico, solamente posible si el sistema educativo incorpora las innovaciones en ese campo y genera conocimientos, actitudes, valores y competencias ajustadas con la apropiación de las innovaciones científico-tecnológicas" ${ }^{21}$.

En síntesis, en el marco del MERCOSUR, el nuevo paradigma productivo requiere, de forma creciente, recursos humanos con una sólida formación general que permita pensar y ejecutar al mismo tiempo. En este cuadro la educación básica de todos los ciudadanos se convierte en una condición decisiva para el crecimiento y la competitividad de las naciones. Además, el fortalecimiento de las políticas y de los programas regionales de formación profesional deberá convertirse en uno de los ejes fundamentales de apoyo a los objetivos básicos del Tratado: Favorecer la libre circulación de bienes, servicios, capitales y personas. El proceso de integración del MERCOSUR reclama la urgente mejora de la formación científica y tecnológica y la actualización de las calificaciones ocupacionales de la fuerza de trabajo, así como el desarrollo de programas de educación ambiental, para la salud y para la educación especial ${ }^{3 \prime \prime}$.

\subsection{La Unión Europea (UE)}

La UE es actualmente la mayor potencia comercial del mundo - aún más grande que el Tratado de Libre Comercio de América del Norte-; representa el 25\% del comercio mundial; su Producto Interno Bruto ronda los 7,200 billones de dólares; agrupa a quince países (Austria, Bélgica, Dinamarca, Finlandia, Francia, Alemania, Grecia, Irlanda, Italia, Luxemburgo, Países Bajos, Portugal, España, Suiza e Inglaterra), con una población total de 370 millones de personas. 
La UE es extraordinaria en más de un sentido: por un lado, en el curso de su corta historia ha crecido de manera acelerada, geográfica (en 1957, fecha de su fundación, eran sólo seis países los que participaban de la Unión; cuarenta años después, se compone de quince, con miras a continuar acogiendo miembros), política e institucionalmente. Por otro, la UE se constituye en el más brillante y exitoso modelo de integración regional en el mundo: sus alcances van mucho más allá de un mero espacio de libre comercio. Configura un mercado único en el que se da la libre circulación de bienes, personas y servicios a través de los quince estados miembros.

Además, la UE es más que una organización intergubernamental, pues cuenta con una serie de instituciones comunes que norman y vigilan la formulación y cumplimiento de los objetivos comunitarios. Así, la jurisdicción de las instituciones de la Unión Europea (por ejemplo, la Comisión Europea y el Consejo Europeo) alcanza y sobrepasa la de los gobiernos y parlamentos de los países miembros.

Los orígenes de la UE se remontan al período posterior de la Segunda Guerra Mundial, un momento en el que Europa en ruinas buscaba reconstruir su economía y evitar la posibilidad de nuevas guerras en su interior. Padres Fundadores de lo que hoy avanza hacia una Unión Política y Monetaria son Robert Shuman, entonces Ministro de Relaciones Exteriores de Francia, y Jean Monnet, notable economista, ambos franceses. Buscando conciliar a los países europeos e intentando sentar las bases de una eventual federación europea, Shuman presentó, el 9 de mayo de 1950, el borrador de un plan encaminado a unificar las industrias del carbón y del acero de Francia y Alemania en el marco de un organismo abierto a todas las naciones democráticas de Europa.

El 18 de abril de 1951, Bélgica, Francia, Italia, Luxemburgo, Países Bajos y la República Federal de Alemania (conocidos después como el grupo de "los Seis"), rubricaron el Tratado de París para formar la primera de las tres Comunidades Europeas: La Comunidad Europea del Carbón y del Acero (CECA). Estimulados por el éxito económico que tuvo este tratado, los Seis, en 1957, firmaron en Roma los tratados que sentaron las bases para la actual UE instituyendo la Comunidad Económica Europea (CEE) y la Comunidad Europea de la Energía Atómica (Euroatom). Los objetivos inmediatos de la CEE eran la expansión económica y la elevación del nivel de vida de los ciudadanos de los países signatarios, por un lado, y la unión política de los pueblos europeos sobre la base del desarrollo armónico de las actividades económicas en el conjunto de la Comunidad, por otro ${ }^{31}$. Por su parte, Euroatom tiene como objetivos favorecer en Europa la utilización de la energía nuclear con fines pacíficos.

Para entender el espíritu que animó a los fundadores de la UE es pertinente citar la presentación del texto del Tratado de 1957: "SU MAJESTAD EL REY DE LOS BELGAS, EL PRESIDENTE FEDERAL DE ALEMANIA, EL PRE- 
SIDENTE DE LA REPÚBLICA FRANCESA, EL PRESIDENTE DE LA REPÚBLICA ITALIANA, SU ALTEZA REAL LA GRAN DUQUESA DE LUXEMBURGO, SU MAJESTAD LA REINA DE LOS PAISES BAJOS, RESUELTOS a sentar las bases de una unión cada vez más estrecha entre los pueblos europeos; DECIDIDOS a asegurar, mediante una acción común, el progreso económico y social de sus respectivos países, eliminando las barreras que dividen Europa; FIJANDO como fin esencial de sus esfuerzos la constante mejora de las condiciones de vida y de trabajo de sus pueblos; RECONOCIENDO que la eliminación de los obstáculos existentes exige de una acción concertada para garantizar un desarrollo económico estable, un intercambio comercial equilibrado y una competencia leal; PREOCUPADOS por reforzar la unidad de sus economías y asegurar su desarrollo armonioso, reduciendo las diferencias entre las diversas regiones y el retraso de las menos favorecidas; DESEOSOS de contribuir, mediante una política comercial común, a la progresiva supresión de las restricciones de intercambios internacionales; PRETENDIENDO reforzar la solidaridad de Europa con los países de ultramar y deseando asegurar el desarrollo de su prosperidad, de conformidad con los principios de la Carta de las Naciones Unidas; RESUELTOS a consolidar, mediante la constitución de este conjunto de recursos, la defensa de la paz y la libertad e invitando a los demás pueblos de Europa que participan de dicho ideal a asociarse a su esfuerzo; HAN DECIDIDO crear una COMUNIDAD EUROPEA [CE]"3.3.

La prioridad de los Tratados Fundadores de la CE fue eliminar las barreras económicas que dividían a los Estados miembros, para luego proceder en el orden de objetivos políticos. Cumplir este objetivo implicaba asegurar que al interior de la CE se verificara una libre circulación de personas, bienes y servicios; es decir, implicaba la creación de una Unión Aduanera, la eliminación de aranceles entre los Estados miembros y el establecimiento de un arancel exterior común. Esta etapa, la primera para la consecución de un Mercado Común, concluyó en julio de 1968. En 1985 la Comisión Europea, en un contexto en el que el proceso de integración europeo había disminuido considerablemente, lanza la idea de superar el Tratado de Roma por medio del establecimiento de un mercado único, sin fronteras interiores, por el que la CEE dejaría de ser una mera zona de libre comercio. Siete años después, el $1^{0}$ de enero de 1993, el Mercado Unico Europeo era ya una realidad, con lo cual la circulación de bienes y servicios al interior de los países miembros de la UE carecía de obstáculos fronterizos, se realizaba como si de un territorio único se tratara. En marzo de 1995, al entrar en vigor el Convenio de Schéngen, el cual eliminó los controles de las fronteras internas (aunque de manera limitada, pues sólo fue adoptado por siete de los países firmantes del convenio), la libre circulación de personas comenzó a cobrar forma.

Hasta la fecha, los objetivos del Mercado Interior se han cumplido en su mayor parte, por lo que Europa se presenta al mundo como un espacio sin obstáculos físicos, técnicos o impositivos en sus fronteras interiores, es decir, 
como un gran espacio unificado. En los próximos años, los objetivos principales de la UE son: "a) la aplicación de las disposiciones del Tratado de Amsterdam" (nuevos derechos de los ciudadanos, libre circulación, empleo, consolidación de las instituciones...); b) la ampliación de la UE, especialmente a los países de Europa Central y oriental candidatos a la adhesión (Agenda 2000 74 ; y c) el lanzamiento del euro ${ }^{35}$ י.3.

Finalmente, es importante traer a cuenta que parte fundamental del proceso de constitución de la UE reside en los derechos que los ciudadanos de las naciones europeas han ido adquiriendo en la nueva realidad socio-política del continente. Estos derechos, que cualquier ciudadano europeo puede hacer valer ante los Tribunales de cada Estado miembro y ante el Tribunal de Justicia Europeo (máximo ente garante del cumplimiento y aplicación de los Tratado de la UE), giran en torno a tres ejes:

1) Los derechos fundamentales, en ellos se estipulan las obligaciones de los Estados miembros para con los derechos de cualquier ciudadano de la UE, se establecen el procedimiento y las penas a imponer en caso de que un Estado miembro viole las normas comunitarias y se sientan las bases para lograr relaciones de igualdad entre los ciudadanos de los Estados miembros;

2) Los derechos inherentes a la libertad de circulación, referentes a la oportunidad de empleo y educación, entre otros, a lo largo del territorio de la UE;

3) Los derechos democráticos de los ciudadanos: derecho de voto, derecho de petición, derecho de transparencia (derecho de todo ciudadano europeo a examinar los procedimientos y acciones de las instituciones europeas) y protección diplomática.

\subsubsection{Políticas económicas}

\subsubsection{Marco General.}

Por ser un proyecto de larga data - un proyecto que desde su fundación en 1957 ha sufrido tres grandes revisiones: en 1987, en 1992 y en 1997, reflejadas en el Acta Unica, el Tratado de la Unión Europea y el Tratado de Amsterdam, -respectivamente-, la UE ha ido adaptando sus políticas económicas a las diversas coyunturas históricas por las que ha atravesado. Demás está decir que, por ejemplo, la constitución del Mercado Unico o la próxima instauración del euro como unidad monetarib única - etapas fundamentales e ineludibles para la fundación de la Comunidad Europea buscada - han estado moduladas por las circunstancias y necesidades de Europa frente a un entorno mundial cambiante. Sin embargo, la UE afirma como su finalidad esencial "una Unión cada vez más estrecha entre los pueblos de Europa, en la cual las decisiones serán tomadas de la forma más próxima posible a los ciudadanos":37. 
Siendo este el espíritu que la anima, la UE reconoce una serie de circunstancias a las que debe hacer frente para consolidar su modelo de integración económica de la mejor manera posible: "La Unión Europea se ve enfrentada a una abrumadora serie de exigencias en el umbral del siglo XXI: rápida evolución de la situación internacional; globalización de la economía mundial y sus consecuencias en el empleo, competitividad y creación de puestos de trabajo; terrorismo, delincuencia y tráfico de drogas; presión migratoria, desequilibrios ecológicos y amenazas a la salud pública"3. . En este marco, "La Comunidad [Europea] tendrá por misión promover, mediante el establecimiento de un mercado común y de una unión económica y monetaria y mediante la realización de las políticas o acciones comunes contempladas [en los Tratados Fundadores revisados], un desarrollo armonioso y equilibrado de las actividądes económicas en el conjunto de la Comunidad, un crecimiento sostenible y no inflacionista que respete el medio ambiente, un alto grado de convergencia de los resultados económicos, un alto nivel de empleo y de protección social, la elevación del nivel y de la calidad de vida, la cohesión económica y social y la solidaridad entre los Estados miembros":39.

\subsubsection{Medidas de política económica.}

Las medidas de política económica de la UE se pueden agrupar en los siguientes apartados ${ }^{411}$ :

\section{Principios constitutivos.}

Se ordena: a) La supresión, entre los Estados miembros, de los derechos de aduana y de las restricciones cuantitativas a la entrada y salida de las mercancías, así como de cualesquiera otras medidas de efecto equivalente; b) Una política comercial común; c) Un mercado interior caracterizado por la supresión de los obstáculos a la libre circulación de mercancías, personas, servicios y capitales; d) Un régimen que garantice que la competencia no será falseada en el mercado interior; e) El fortalecimiento de la competitividad de la industria de la Comunidad; f) Creación de una política en el ámbito de la cooperación al desarrollo; g) La asociación de los países y territorios de Ultramar, a fin de incrementar los intercambios; h) Una contribución al fortalecimiento de la protección de los consumidores.

La acción de los Estados miembros y de la Comunidad Europea incluirá la adopción de una política económica que se fundamentará en la estrecha coordinación de las políticas económicas, en el mercado interior y en la definición de objetivos comunes, lo cual se llevará a cabo respetando los principios de una economía abierta y de libre mercado. Esta acción implicará la fijación irrevocable de tipos de cambio orientada al establecimiento de una moneda única (el euro), la definición y aplicación de una política monetaria y de tipos de cambio 
única, cuyo objetivo primordial sea mantener la estabilidad de precios y, sin desmedro de lo anterior, el apoyo a la política económica general de la Comunidad. La aplicación de estas medidas por parte de los Estados miembros y de la Comunidad deberá tener como referente el respeto de los siguientes principios: precios estables, finanzas públicas y condiciones monetarias sólidas y balanza de pagos estable.

\section{Libre circulación de mercancías.}

La Comunidad se basará en una unión aduanera que abarcará la totalidad de los intercambios de mercancías y que supondrá, por un lado, la prohibición, entre los Estados miembros, de los derechos de aduana de importación y exportación, y, por otro, la adopción de un arancel aduanero común en sus relaciones con terceros países.

Unión Aduanera. Los estados miembros se abstendrán de establecer entre sí nuevos derechos de aduana de importación y exportación, y de aumentar los que ya estén aplicando en sus relaciones recíprocas; éstos, por el contrario, serán suprimidos progresivamente

En el establecimiento de un arancel aduanero común, la Comisión Europea se guiará por: i) La necesidad de promover los intercambios comerciales entre los Estados miembros y terceros países; ii) La evolución de las condiciones de competencia dentro de la comunidad, en la medida en que dicha evolución tenga por efecto el incremento de la capacidad competitiva de las empresas; iii) Las necesidades de abastecimiento de la Comunidad en materias primas y productos semielaborados, procurando que no se falseen las condiciones de competencia de los productos acabados; y iv) La necesidad de evitar perturbaciones graves en la vida económica de los Estados miembros y garantizar un desarrollo racional de la producción y una expansión del consumo en la Comunidad.

Supresión de las restricciones cuantitativas entre los Estados miembros. Se impone a los Estados miembros la prohibición de crear o aumentar restricciones cuantitativas a la importación y exportación; además, éstas deberán ser eliminadas progresivamente. Los Estados miembros adecuarán progresivamente los monopolios de carácter comercial de tal modo que quede asegurada la exclusión de toda discriminación entre los nacionales de los Estados miembros respecto de las condiciones de abastecimiento y de mercado. Esta disposición será aplicable a cualquier organismo mediante el cual un Estado miembro, ya sea por ley o de facto, directa o indirectamente, controle, dirija o influya en las importaciones o exportaciones al interiór de la Comunidad; quedan también sujetos a la aplicación de esta medida los monopolios cedido por el Estado a terceros.

Agricultura.

Los objetivos de la política agrícola común, en el marco del mercado común, serán: i) Incrementar la productividad agrícola fomentando el progreso técnico, 
asegurando el desarrollo racional de la producción agrícola, así como el empleo óptimo de los factores de producción, en particular, de la mano de obra; ii) Garantizar así un nivel de vida equitativo a la población agrícola, en especial, mediante el aumento de la renta individual de los que trabajan en agricultura; iii) Estabilizar los mercados; iv) Garantizar la seguridad de los abastecimientos; y v) asegurar al consumidor suministros a precios razonables.

\section{Libre circulación de personas, capitales y servicios: capital y pagos.}

Los Estados miembros suprimirán progresivamente entre sí, en la medida necesaria para el buen funcionamiento del mercado común, las restricciones a los movimientos de capitales pertenecientes a personas residentes en los Estados miembros, así como las restricciones sobre los pagos corrientes relacionados con los movimientos de capitales entre aquéllos. La no discriminación será principio rector en el caso de que un Estado miembro aplique a los movimientos de capital liberalizados su regulación interna relativa al mercado de capitales y al crédito. Además, se prohibe la introducción de nuevas restricciones o la agudización de las que ya están siendo aplicadas en los Estados miembros. No obstante, la aplicación de estas políticas debe realizarse sin perjuicio de la aplicación a terceros países de las restricciones existentes hasta la fecha en materia de movimientos de capitales que supongan inversiones directas, incluidas las inmobiliarias, el establecimiento, la prestación de servicios financieros o la admisión de valores en los mercados de capitales.

\section{Normas sobre competencia.}

Se declara como incompatible al mercado común y quedan prohibidos todos los acuerdos entre empresas, las decisiones de asociaciones de empresas y las prácticas concertadas que puedan afectar al comercio entre los Estados miembros y que tengan por objeto o efecto impedir, restringir o falsear el juego de la competencia dentro del mercado común; así también queda prohibida la explotación abusiva, por parte de una o más empresas, de una posición dominante en el mercado común o en una parte sustancias del mismo. Las prácticas a suprimir por estas prohibiciones son: i) Imponer directa o indirectamente precios de compra, de venta u otras condiciones de transacción no equitativas; ii) Limitar la producción, el mercado o el desarrollo técnico en perjuicio de los consumidores; iii) Aplicar a terceros contratantes condiciones desiguales para prestaciones equivalentes, que ocasionen a éstos una desventajarcompetitiva; iv) Subordinar la celebración de contratos a la aceptación, por los otros contratantes, de prestaciones suplementarias que, por su naturaleza o según usos mercantiles, no guarden relación alguna con el objeto de dichos contratos.

En relación a prácticas de dumping comprobadas dentro del mercado común, la Comisión Europea, a instancia de un Estado miembro o de cualquier parte 
interesada, dirigirá recomendaciones al autor de aquéllas para ponerles fin. Si se diera el caso de que dichas prácticas continuaran, la Comisión Europea autorizará al Estado miembro perjudicado para que adopte las medidas de protección pertinentes. Por otra parte, se entenderán como incompatibles con el mercado común los intercambios comerciales entre Estados miembros, las ayudas otorgadas por los Estados o mediante fondos estatales, que falseen o amenacen falsear la competencia favoreciendo a determinadas empresas. Quedan fuera de esta política las ayudas de carácter social no discriminatorias concedidas a los consumidores individuales, las ayudas por desastres naturales o situaciones excepcionales, las ayudas orientadas a nivelar desigualdades de desarrollo económico entre regiones, las ayudas destinadas a fomentar la realización de un proyecto de interés comunitario y las encaminadas a promover la cultura y la conservación del patrimonio.

\section{Disposiciones fiscales.}

Ningún Estado miembro gravará directa o indirectamente los productos de los demás Estados miembros con tributos internos, cualquiera que sea su naturaleza, superiores a los que graven directamente o indirectamente los productos nacionales similares, o que puedan proteger indirectamente otras producciones. Adicionalmente, los productos exportados al territorio de uno de los Estado miembros no podrán beneficiarse de ninguna devolución de tributos internos superior al importe de aquellos con que hayan sido gravados directa $o$ indirectamente. Siempre y cuando no se perjudiquen las dos disposiciones anteriores, los Estados miembros que perciban el impuesto sobre el volumen de negocios con arreglo al sistema de imposición acumulativa en cascada podrán proceder a la fijación de tipos medios por producto o grupos de productos, respecto de los tributos internos que graven los productos importados o de las devoluciones concedidas a los productos exportados. En cuanto a los tributos distintos de los impuestos sobre el volumen de negocios, los impuestos sobre consumos específicos y los otros impuestos indirectos, no se podrán conceder exoneraciones ni reembolsos a las exportaciones a los demás Estados miembros ni imponer gravámenes compensatorios a las importaciones procedentes de los Estados miembros, a menos que las medidas proyectadas hubieren sido previamente aprobadas por el Consejo Europeo.

\section{Política Económica.}

Los Estados miembros llevarán a cabo sus políticas económicas con vistas a contribuir a la realización de los objetivos de la Comunidad Europea y actuarán respetando el principio de una economía de mercado abierta y de libre competencia, tratando de evitar, como prioridad, déficits públicos excesivos. Las entidades encargadas de vigilar las economías de los Estados miembros, garantizar una coordinación más estrecha de éstas y una convergencia sostenida de sus 
resultados económicos, y elaborar un proyecto de orientaciones generales para las políticas económicas, son la Comisión, el Consejo Europeo y el Parlamento Europeo, cada una con funciones específicas en vistas a una supervisión multilateral de la economía de los Estados miembros.

La Comisión examinará la observancia de la disciplina presupuestaria de los Estados miembros atendiendo a dos criterios: i) Si la proporción entre el déficit público previsto o real y el PIB sobrepasa un valor de referencia, a menos que la proporción haya descendido sustancial y continuadamente y llegado a un nivel que se aproxime al valor de referencia, o que el valor de referencia se sobrepase sólo excepcional y temporalmente, y la proporción se mantenga cercana al valor de referencia; ii) Si la proporción entre la deuda pública y el PIB rebasa un valor de referencia, a menos que la proporción disminuya suficientemente y se aproxime a un ritmo satisfactorio de referencia.

Queda prohibida la autorización o concesión de cualquier otro tipo de créditos por el Banco Central Europeo (BCE) y por los bancos centrales de los Estados miembros a favor de instituciones u organismos comunitarios, Gobiernos centrales, autoridades regionales o locales u otras autoridades públicas, organismos de Derecho público o empresas públicas de los Estados miembros, así como la adquisición directa a los mismos de instrumentos de deuda por el BCE o los bancos centrales.

La Comunidad no asumirá ni responderá por los compromisos de los Gobiernos centrales, autoridades regionales o locales u otras autoridades públicas, organismos de Derecho público o empresas públicas de los Estados miembros, sin perjuicio de las garantías financieras mutuas para la realización conjunta de proyectos específicos. Los Estados miembros no asumirán ni responderán por los compromisos de los Gobiernos centrales, autoridades regionales o locales u otras autoridades públicas, organismos de Derecho público o empresas públicas de otro Estado miembro, sin perjuicio de las garantías financieras mutuas para la realización conjunta de proyectos específicos.

\section{Política Monetaria.}

El objetivo principal del Sistema Europeo de Bancos Centrales (SEBC) (compuesto por el BCE y los bancos centrales de los Estados miembros) será mantener la estabilidad de precios. Sin perjuicio de este objetivo, el SEBC apoyará las políticas económicas generales de la Comunidad con el fin de contribuir a la realización de los objetivos comunitarios establecidos, y actuará con arreglo al principio de una economía de mercado abierta y de libre competencia, fomentando una eficiente asignación de recursos. Las funciones básicas del SEBC serán: i) Definir y ejecutar la política monetaria de la Comunidad; ii) Realizar operaciones de divisas; iii) Poseer y gestionar las reservas oficiales de divisas de los Estados Miembros; iv) Promover el buen funcionamiento de los sistemas de pago. 
Con el fin de garantizar su independencia y despejar la posibilidad de perturbaciones externas, en el ejercicio de las facultades y en el desempeño de las funciones y obligaciones que les asignan el presente Tratado y los Estatutos del SEBC, ni el BCE, ni los bancos centrales nacionales, ni ninguno de los miembros de sus órganos rectores podrán solicitar o aceptar instrucciones de las instituciones y organismos comunitarios, ni de los Gobiernos de los Estados miembros, ni de ningún otro órgano. Estos últimos, a su vez, se comprometen a respetar este principio y a no tratar de influir en los miembros de los órganos rectores del BCE y de los bancos centrales nacionales en el ejercicio de sus funciones.

En lo relacionado a las políticas de sistema de tipos de cambio del euro, será el Consejo - sobre la base de una recomendación del BCE o de la Comisión y previa consulta al BCE, y teniendo siempre como prioridad la estabilidad de los precios - quien podrá: celebrar acuerdos formales; adoptar, ajustar o abandonar tipos centrales del euro en el sistema de tipos de cambio; formular orientaciones generales para la política de tipos de cambio y decidir sobre las modalidades de negociación y celebración de acuerdos en materia de régimen monetario o de régimen cambiario.

\section{Política comercial común.}

La política comercial común deberá tener en cuenta la incidencia favorable que la supresión de los derechos de aduana entre los Estados miembros pueda tener en el aumento de la capacidad competitiva de las empresas de dichos Estados. En la medida necesaria para evitar que esta competencia se falsee, los regímenes de ayudas concedidas por los Estados miembros a las exportaciones hacia terceros países se armonizarán progresivamente. Estas disposiciones no se aplicarán a las devoluciones de los derechos de aduana o de las exacciones de efecto equivalente ni a las devoluciones de tributos indirectos, incluidos los impuestos sobre el volumen de negocios, los impuestos sobre consumos específicos y los demás impuestos indirectos, concedidas en el momento de la exportación de una mercancía desde un Estado miembro a un tercer país, en la medida en que dichas devoluciones no sean superiores a los gravámenes que directa o indirectamente recaen sobre los productos exportados.

La política comercial común se basará en principios uniformes, particularmente en lo que se refiere a las modificaciones arancelarias, la celebración de acuerdos arancelarios y comercialeś, la consecución de la uniformidad de las medidas de liberalización, la política de exportación, así como las medidas de protección comercial, y, entre ellas, las que deban adoptarse en caso de dumping y subvenciones. 


\section{Industria.}

La Comunidad y los Estados miembros asegurarán la existencia de las condiciones necesarias para la competitividad de la industria comunitaria. Para tal fin, dentro de un sistema de mercados abiertos y competitivos, su acción estará encaminada a: i) Acelerar la adaptación de la industria a los cambios estructurales; ii) Fomentar un entomo favorable a la iniciativa y al desarrollo de las empresas en el conjunto de la Comunidad, y, en particular, de las pequeñas y medianas empresas; iii) Fomentar un entorno favorable a la cooperación entre empresas; iv) Favorecer un mejor aprovechamiento del potencial industrial de las políticas de innovación, de investigación y de desarrollo tecnológico.

\section{Cohesión económica.}

A fin de promover un desarrollo armonioso del conjunto de la Comunidad, ésta desarrollará y proseguirá su acción encaminada a reforzar su cohesión económica. La comunidad se propondrá, en particular, reducir las diferencias entre los niveles de desarrollo de las diversas regiones y el retraso de las regiones menos favorecidas, incluidas las zonas rurales. Estos objetivos deberán ser tomados en cuenta por los Estados miembros y la Comunidad al diseñar su política económica y al desarrollar el mercado interior.

El Fondo Europeo de Desarrollo Regional será la entidad destinada a contribuir a la corrección de los principales desequilibrios regionales dentro de la Comunidad mediante una participación en el desarrollo y en el ajuste estructural de las regiones menos desarrolladas y en la reconversión de las regiones industriales en declive.

\section{Medio Ambiente.}

La política de la Comunidad en el ámbito del medio ambiente contribuirá a alcanzar los siguientes objetivos: i) La conservación, la protección y la mejora de la calidad del medio ambiente; ii) La protección de la salud de las personas; iii) La utilización prudente y racional de los recursos naturales; y iv) El fomento de medidas a escala internacional destinadas a hacer frente a los problemas regionales o mundiales del medio ambiente. Esta política se basará en los principios de cautela y de acción preventiva, en el principio de corrección de los atentados al medio ambiente, preferentemente en la fuente misma, y en el principio de que quien contamina paga.

\subsubsection{Políticas sociales}

\subsubsection{Marco general.}

En coherencia con el proceso de integración y unión económica, la Unión Europea ha trazado las políticas sociales necesarias para definir y dar cuerpo al 
perfil del ciudadano europeo. Dentro de estas políticas se enfatizan aquellas relacionadas con los nuevos derechos que surgen de la ciudadanía europea: derecho de voto en la elección de los funcionarios que integran las instituciones de la unión y derecho de libre circulación al interior de los países que comprenden la UE, entre otros. Es importante no perder de vista que, al igual que en las dinámicas económicas, se prevén, como principios rectores del proceso, la no discriminación y la consolidación de los mecanismos necesarios para asegurar la igualdad de oportunidades para todos los ciudadanos de la Unión.

\subsubsection{Medidas de política social}

A continuación se presentan, brevemente, las políticas sociales que rigen y regirán a la UE hasta su consolidación definitiva:

\section{Ciudadanía de la Unión.}

Será ciudadano de la Unión toda persona que ostente la nacionalidad de un Estado miembro. Los derechos y deberes de los que serán titulares los ciudadanos de la Unión son: i) Derecho a circular y residir libremente en el territorio de los Estados miembros; ii) Todo ciudadano de la Unión que resida en un Estado miembro del que no sea nacional tendrá derecho a ser elector y elegible en las elecciones municipales y en las elecciones al Parlamento Europeo en el Estado miembro en el que resida, en las mismas condiciones que los nacionales de dicho Estado; iii) Todo ciudadano de la Unión podrá acogerse, en el territorio de un tercer país en el que no esté representado el Estado miembro del que sea nacional, a la protección de las autoridades diplomáticas y consulares de cualquier Estado miembro, en las mismas condiciones que los nacionales de dicho Estado; iv) Todo ciudadano de la Unión tendrá el derecho de petición ante el Parlamento Europeo.

\section{Libre circulación de trabajadores.}

La libre circulación de los trabajadores dentro de la Unión supondrá la abolición de toda discriminación por razón de nacionalidad, con respecto al empleo, la retribución y las demás condiciones de trabajo. Esta libre circulación implicará, además, el derecho de: i) Responder a ofertas efectivas de trabajo; ii) Desplazarse libremente para este fin en el territorio de los Estados miembros; iii) Residir en uno de los Estados miembros con objeto de ejercer en él un empleo, de conformidad con las disposiciones aplicables al empleo de los trabajadores nacionales; iv) Permanecer en el territorio de un Estado miembro después de haber ejercido en él un empleo.

Además de que se facilitará entre los Estados miembros el intercambio de trabajadores jóvenes, se adoptarán, en materia de seguridad social, las medidas necesarias para el establecimiento de la libre circulación de trabajadores, creando 
un sistema que permita garantizar a los trabajadores migrantes y a sus derechohabientes: por un lado, la acumulación de todos los períodos tomados en consideración por las distintas legislaciones nacionales para adquirir y conservar el derecho a las prestaciones sociales, así como para el cálculo de éstas; y, por otro, el pago de las prestaciones a las personas que residan en los territorios de los Estados miembros.

\section{Política social de educación, de formación profesional y de juventud.}

Los Estados miembros convienen en la necesidad de promover la mejora de las condiciones de vida y de trabajo de los trabajadores, a fin de conseguir su equiparación por la vía del progreso. La Comisión tendrá por misión promover una estrecha colaboración entre los Estados miembros en el ámbito social, particularmente en las materias relacionadas con: el empleo, el Derecho del trabajo y las condiciones de trabajo, la seguridad social, la protección contra los accidentes de trabajo y las enfermedades profesionales, la higiene del trabajo, el derecho a la sindicalización y las negociaciones colectivas entre empresarios y trabajadores.

Cada Estado miembro deberá garantizar la aplicación del principio de igualdad de retribución entre los trabajadores masculinos y femeninos para un mismo trabajo. Esta igualdad de retribución significa que: i) La retribución establecida para un mismo trabajo remunerado por unidad de obra realizada se fija sobre la base de una misma unidad de medida; y ii) La retribución establecida para un trabajo remunerado por unidad de tiempo es igual para un mismo puesto de trabajo. Para mejorar las posibilidades de empleo de los trabajadores en el mercado interior y contribuir así a la elevación del nivel de vida, se crea un Fondo Social Europeo destinado a fomentar las oportunidades de empleo y la movilidad geográfica y profesional de los trabajadores, así como a facilitar su adaptación a las transformaciones industriales y a los cambios de los sistemas de producción, especialmente mediante la formación y la reconversión profesionales.

La comunidad contribuirá al desarrollo de una educación de calidad fomentando la cooperación entre los Estados miembros y, de ser necesario, apoyando y complementando la acción de éstos en el pleno respeto de sus responsabilidades en cuanto a los contenidos de la enseñanza y a la organización del sistema educativo, así como de su diversidad cultural y lingüística. La acción de la comunidad se encaminará a: i) Desarrollar la dimensión europea en la enseñanza, especialmente a través del aprendizaje y de la difusión de las lenguas de los Estados miembros; ii) Favorecer la movilidad de estudiantes y profesores, fomentando en particular el reconocimiento académico de los títulos y de los períodos de estudios; iii) Promover la cooperación entre los centros docentes; iv) incrementar el intercambio de información y de experiencia sobre las cuestiones comunes a los sistemas de formación de los Estados miembros; v) Favorecer el 
incremento de los intercambios de jóvenes y de animadores socio-educativos; vi) Fomentar el desarrollo de la educación a distancia.

En lo relacionado al desarrollo de una política de formación profesional, la acción de la Comunidad se encaminará a: i) Facilitar la adaptación a las transformaciones industriales, especialmente mediante la formación y la reconversión profesionales; ii) Mejorar la formación profesional inicial y permanente, para facilitar la inserción y la reinserción profesional en el mercado laboral; iii) Facilitar el acceso a la formación profesional y favorecer la movilidad de los educadores y de las personas en formación; iv) Estimular la cooperación en materia de formación entre centros de enseñanzas y empresas; v) Incrementar el intercambio de información y de experiencias sobre las cuestiones comunes a los sistemas de formación de los Estados miembros.

\section{Cultura.}

La Comunidad contribuirá al florecimiento de las culturas de los Estados miembros, dentro del respeto de su diversidad nacional y regional, poniendo de relieve al mismo tiempo el patrimonio cultural común. La acción de la Comunidad favorecerá la cooperación entre Estados miembros en los siguientes ámbitos: i) La mejora del conocimiento y la difusión de la cultura y la historia de los pueblos europeos; ii) La conservación y protección del patrimonio cultural de importancia europea; iii) Los intercambios culturales no comerciales; iv) La creación artística y literaria, incluido el sector audiovisual.

\section{Salud pública.}

La Comunidad contribuirá a la consecución de un alto nivel de protección de la salud humana fomentando la cooperación entre los Estados miembros y, cuando fuera necesario, apoyando la acción de los mismos. La acción de la Comunidad se encaminará a la prevención de las enfermedades, especialmente de las más graves y ampliamente difundidas, incluida la toxicomanía, apoyando la investigación de su etiología y de su transmisión, así como la información y la educación sanitarias.

\subsection{Asociación de Naciones del Sudeste Asiático (ASEAN)}

La Asociación de Naciones del Sudeste Asiático (ASEAN, por sus siglas en inglés) fue establecida el 8 de agosto de 1967 en Bangkok, Tailandia, con la firma de la Declaración de Bangkok por parte de sus cinco países miembros fundadores: Indonesia, Malasia, Filipinas, Singapur y Tailandia. En un principio, la ASEAN fue creada con el objetivo de generar una estrategia defensiva frente al peligro del avance del comunismo ${ }^{41}$. Brunei Darussalam se incorporó el 8 de enero de 1984 y Vietman se convirtió en el séptimo miembro el 28 de julio de 1995. En el corto plazo, ASEAN se expande gradualmente, ya que a Papua 
Nueva Guinea, Camboya y Birmania se les ha concedido el status de observadores, con lo que la Asociación avanza hacia la integración del total de los países de la península de Indochina.

La Declaración de Bangkok ${ }^{42}$ sintetiza el compromiso conjunto de los países miembros para promover la cooperación económica y el bienestar de los pueblos de la región. Este documento fundacional establece las líneas estratégicas del ASEAN y define los objetivos fundamentales de la organización: "i) Acelerar el desarrollo económico, el progreso social y el desarrollo cultural en la región a través de un esfuerzo común, en espíritu de igualdad y compañerismo, para consolidar la fundación de una próspera y pacífica comunidad de las Naciones del Sudeste Asiático; ii) Promover la paz y la estabilidad regionales a través de un respeto permanente de la justicia y del derecho en la relación entre los países de la región y de la adherencia a los principios de la carta de las Naciones Unidas; iii) Promover la colaboración activa y la ayuda mutua en materias de interés común en los campos económicos, sociales, culturales, técnicos, científi$\cos$ y administrativos; iv) Proporcionar ayuda recíproca en la línea de entrenamiento y recursos de investigación en las esferas educativa, profesional, técnica y administrativa; v) Colaborar eficazmente para la óptima utilización de la agricultura y la industria, la expansión de su comercio -incluyendo el estudio de los problemas de comercio internacional de mercancías-, la mejora de los recursos de transporte y comunicación y el crecimiento de los estándares de vida de su población; vi) Promover estudios sobre el Sudeste Asiático; vii) Mantener una cercana y beneficiosa cooperación con las organizaciones internacionales y regionales con objetivos y propósitos similares, y explorar todas las vías para una colaboración más estrecha entre sí mismos"43.

A lo largo de casi treinta años de existencia y tras un largo período correspondiente a la etapa de la Guerra Fría-, durante el cual el centro principal de actividad recayó en las esferas políticas y de seguridad, ASEAN ha ido desarrollando de manera más armónica sus diversos ámbitos de acción (especialmente el área económica), constituyéndose en la principal instancia integradora del Sudeste de Asia. La globalización y el desarrollo de la economía mundial conllevan a que en la actualidad el ASEAN adopte como objetivo la intensificación del crecimiento económico a través de la cooperación en la región ${ }^{44}$. Reflejo de ello es la decisión de acelerar la implementación del AFTA (Area de Libre Comercio del ASEAN, por sus siglas en inglés).

El crecimiento qùe los países de ASEAN experimentaron durante la década de los años ochenta y los primeros de los noventa (que por su cariz vertiginoso llevó a que fueran llamados los "tigres asiáticos", hizo que el bloque económico fuera considerado como un modelo a imitar por los países subdesarrollados para alcanzar altos niveles de desarrollo económico en corto tiempo. Así, los países de ASEAN duplicaron su riqueza en diez años, pasando de 177.000 millones de 
dólares en 1980 a 320.000 millones de dólares en 1990, mientras que el PIB medio per capita también se duplicó durante el mismo período. Por otra parte, los Estados miembros de ASEAN sostuvieron, entre 1995 y 1996, una tasa de crecimiento del 7.5\%, convirtiendo al Sudeste Asiático en una de las regiones de mayor crecimiento económico en el mundo. En 1997, el Banco Mundial preveía que, para el año 2002, ASEAN sería uno de los cinco mayores centros económicos, después del TLCAN, la Unión Europea, China y Japón. Sin embargo, a principios de julio de 1997, la abrupta devaluación de la moneda de Tailandia, seguida de un "efecto dominó" que afectó — en algunos casos de manera desastrosa - las bolsas financieras no sólo de los países Asiáticos ${ }^{45}$, sino también de un buen número de países desarrollados o en vías de desarrollo, planteó serias dudas acerca del alcance y fortaleza de lo que hasta entonces se daba por llamar el "milagro asiático".

El modelo de desarrollo de los países del Sudeste Asiático se centra, tal como señala el Instituto de Estudios Latinoamericanos, "en las exportaciones, cuyos pilares fundamentales son las altas tasas de ahorro interno y las fuertes corrientes de inversión productiva. La inversión extranjera directa ha jugado un rol básico en las estrategias de desarrollo de esos países. En las décadas de los sesenta y setenta, se siguieron programas de industrialización basados en la dotación de recursos naturales y en la protección de las nacientes industrias. En los años ochenta diversos factores condujeron a una explícita orientación a favor de las exportaciones industriales, basadas en un papel cada vez más importante de la inversión directa externa"4h. Es interesante observar que en los países del ASEAN, al contrario de los países en los que se han aplicado políticas de reducción y modernización del Estado, "las estrategias de reestructuración, apertura y crecimiento vía exportaciones adoptadas...si bien fueron orientadas en función de la economía de mercado, no redujeron el papel del Estado...[Éste] fue redimensionado, pero mantuvo siempre un papel sumamente activo e intervencionista, en su carácter de agente articulador de las relaciones económicas y sociales y orientador e impulsor del crecimiento, el desarrollo y la competitividad externa. El Estado -en cooperación y concertación con el sector empresario- ha prestado particular atención a la formación y capacitación de los recursos humanos...y posteriormente, a la generación de tecnologías avanzadas, modificando y elevando su perfil productivo y por ende, su forma de inserción en el comercio internacional. De igual manera, el Estado ha realizado un especial esfuerzo...en pro de la organización de un sistema financiero global y por el desarrollo de un potente mercado de capitales"47.

\subsubsection{Políticas económicas}

\subsubsection{Marco general.}

La cooperación económica en ASEAN no sólo está relacionada con políticas de liberalización del comercio, sino también con la facilitación de éste, con 
medidas antifronterizas y actividades de promoción de inversiones. Además, se están abriendo nuevas vías de cooperación, en áreas como servicios y derechos de propiedad intelectual. Las actividades de la cooperación económica de ASEAN en la década de los noventa incluyen lo siguiente: "i) Implementar por completo el Tratado de Libre Comercio de ASEAN (AFTA); ii) Desarrollar la región hacia una base global para la manufactura de productos de valor agregado y tecnológicamente sofisticados, dirigidos a servir a la región y a los mercados mundiales; iii) Elevar la eficacia industrial a través de la explotación de las ventajas de ubicación, basándose en los principios de compartir mercados y recursos; iv) Aumentar el atractivo de la región para la inversión y como un destino turístico; v) Cooperar en alcanzar un mayor desarrollo en la infraestructura, lo cual contribuirá a un ambiente empresarial más eficiente; vi) Asegurar que los valiosos recursos de la región (minerales, energía, recursos forestales y otros) sean explotados efectiva y eficientemente" ${ }^{\text {"48. }}$.

\subsubsection{Medidas de política económica.}

Brevemente, las políticas económicas que están actualmente en vigencia en ASEAN se agrupan en las siguientes áreas ${ }^{4 \prime}$ :

\section{Area de Libre Comercio de ASEAN.}

Con el AFTA se busca complementar la posición de ASEAN como una base de producción competitiva enfocada a servir al mercado global. Para este fin, se persigue expandir el comercio al interior del ASEAN, posibilitando así tanto la especialización como economías de escalas. Además, la consolidación de un mercado único tiene como meta atraer un flujo de inversión extranjera directa. El principal mecanismo para realizar el AFTA es el proyecto de Tarifa Preferencial Común Efectiva (CEPT, por sus siglas en inglés), el cual, lanzado el 1 de enero de 1993, cubre tanto los productos manufacturados como los agrícolas. La cobertura del CEPT es siempre la más amplia en cualquier arreglo comercial de la ASEAN. Así, más de un $\mathbf{9 0 \%}$ del total de las líneas de tarifas de la Asociación ya están incluidas en el CEPT. Estas líneas de tarifas constituyen más de un $81 \%$ de los valores comerciales intra-ASEAN. EI CEPT norma una reducción de las tarifas para todos los productos de una Lista de Inclusión, y la eliminación de las restricciones cuantitativas y de otras barreras no arancelarias. Se establece que, para el año 2003, todas las tarifas de los productos en la Lista de Inclusión no deberán ser más altas que un $5 \%$.

Bajo el principio de regionalismo abierto, ASEAN busca establecer vinculaciones regionales con otros tratados de comercio regional. Hasta la fecha, las actividades en este orden han incluido la creación de un compendio aduanal, intercambio de información sobre estándares, incluyendo trabajo cooperativo en ISO 14000 y colaboración en comercio y bases de datos de inversiones. Las 
políticas de acercamiento con otros bloques regionales se están llevando a cabo con: el Acuerdo de Libre Tratado Norteamericano (NAFTA), el Mercado Común del Sur (MERCOSUR), la Asociación de Libre Comercio Europea (EFTA) y la Comunidad de Desarrollo Sudafricano.

\section{Cooperación en Desarrollo Industrial.}

Las políticas de cooperación industrial han sido diseñadas con el objetivo de desarrollar la competitividad industrial de la región. Esquemas de cooperación industrial, basados en los principios de intercambio de recursos y mercados compartidos, han sido introducidos para facilitar una efectiva explotación de las economías a escala y la complementariedad de las ventajas de ubicación de la región. Estos esquemas son: i) ASEAN Industrial Projects (AIP), cuyo objetivo es establecer proyectos regionales industriales a gran escala que satisfagan las necesidades básicas de la región y aseguren una mayor eficiencia en el uso de sus recursos; ii) ASEAN Industrial Complementation Scheme (AIC) y Brand-to-Brand Complementation Scheme (BBC), ambos enfocados al sector automotriz, fueron creados para promover la complementación industrial entre compañías pertenecientes a los Estados miembros. El BBC está relacionado con la producción e intercambio de partes y componentes automotrices para facilitar una especialización horizontal en la producción de éstos en la región; iii) ASEAN Industrial Joint Venture Scheme (AIJV), cuyo fin es alentar una mayor inversión hacia y dentro de la región, y aumentar la producción industrial a través de intercambio de recursos y actividades de mercados compartidos; iv) Basic Agreement on the ASEAN Industrial Cooperation (AICO), el cual se enfoca a promover actividades conjuntas de manufacturas entre compañías que operan al interior de ASEAN.

\section{Cooperación en Finanzas y Bancos.}

La cooperación en el área de las finanzas está enfocada a brindar un apoyo al AFTA, el AICO y el Area de Inversión de ASEAN (AIA), entre otros. Se tiene como política establecer un marco institucional que complemente la cooperación en varias áreas, incluyendo el ámbito bancario, mercados de desarrollo financiero y de capital, asuntos aduanales, asuntos de seguros, asuntos de impuestos y finanzas públicas, cooperación en políticas monetarias y desarrollo del recurso humano en el sector finanzas. También se han firmado Acuerdos Aduanales que contienen cláusulas que facilitarán el comercio intraregional y el flujo de inversiones. Estos Acuerdos estipulan, además, esfuerzos anticontrabando y actividades de control de aduanas, asistencia técnica mutua, modemización aduanal y actualización de los servicios aduaneros para lograr enfrentar los retos presentes y futuros. Otras entidades relacionadas con las finanzas, tales como los reguladores de seguros, mercados de capital, impuestos y autoridades del banco central, han sido animados a establecer un forum para el fortalecimiento de las actividades de cooperación en cada uno de los subsectores financieros. 


\section{Cooperación en Inversión.}

Las políticas relacionadas con la Inversión Extranjera Directa (IED) están plasmadas en el AIA, cuyo objetivo es ayudar a que ASEAN atraiga más grandes y substanciales niveles de flujo de IED hacia dentro y entre los Estados miembros de la región. En este marco, algunas de las políticas que ya han sido implementadas con éxito son: i) Un Plan de Acción sobre Cooperación y Promoción de Inversión Extranjera Directa e Inversión Intra-ASEAN; ii) Un Programa de Trabajo sobre Cooperación y Promoción de Inversión Extranjera Directa; iii) El mejoramiento del Protocolo del Acuerdo ASEAN sobre la Promoción y Protección de Inversiones; iv) Talleres conjuntos anuales donde se entrena a los funcionarios que diseñan políticas de inversiones para ASEAN; v) Un estudio comprensivo sobre la promoción de la IED; y vi) Una mesa redonda de alto nivel para la formulación de Planes Estratégicos sobre cooperación y promoción de IED en ASEAN; vii) un seminario de expertos en la promoción de IED en el contexto del AIA.

\section{Cooperación en energía.}

Con el objetivo de que ASEAN se convierta en una región de importaciones netas de petróleo para el final del siglo, la acción colectiva de la región está orientada a asegurar una mayor seguridad y sustentabilidad del abastecimiento de energía a través de la diversificación, desarrollo y conservación de los recursos, el uso eficiente de energía y una amplia aplicación de tecnologías amigables para el medio ambiente. Los esfuerzos de cooperación en esta área hacen también énfasis en la realización de acuerdos regionales de interconexión eléctrica y de gas natural.

\section{Cooperación en turismo.}

La cooperación en turismo está enfocada a: i) Desarrollar y promover a la región como un destino turístico con atracciones de clase mundial, con estándares y facilidades internacionales; ii) Alcanzar la mayor simplificación posible en los viajes intra-ASEAN; iii) Establecer un área de libre comercio en servicios turísticos; y iv) Promover un desarrollo sostenido del rubro. Los esfuerzos conjuntos de los Estados miembros se basan en una política de coordinación y/o armonización en áreas tales como inversión, planes de desarrollo turístico, recursos humanos y preservación cultural y ambiental.

\section{Sector Privado.}

ASEAN reconoce la importancia del papel que el sector privado ha jugado en el éxito de la implementación de varios programas de cooperación económica. El sector privado es entendido como un motor de crecimiento y se le ha urgido a participar activamente en el proceso de cooperación económica. En este escenario, 
se han establecido canales de consulta regulares entre las instituciones estatales y los representantes de las cámaras de comercio e industria de ASEAN.

\section{Medio Ambiente ${ }^{50}$.}

El Plan Estratégico de Acción sobre Medio Ambiente tiene los siguientes objetivos: i) Introducir medidas políticas y promover el desarrollo institucional para alentar la integración de los factores ambientales en todos los procesos de desarrollo, tanto a nivel nacional como regional; ii) Establecer objetivos de largo plazo sobre calidad ambiental y trabajar para alcanzar estándares armonizados de calidad ambiental; iii) Armonizar el diseño de políticas, complementar la cooperación técnica y operacional sobre materia ambiental, y desarrollar acciones conjuntas para hacer frente a problemas ambientales comunes; y iv) Estudiar las implicaciones del AFTA sobre el medio ambiente y tomar pasos para la integración de políticas de comercio concretas con políticas ambientales concretas.

Para alcanzar estos objetivos, serán buscadas las siguientes estrategias y acciones: i) Apoyar el desarrollo de un marco de trabajo regional para integrar preocupaciones ambientales y de desarrollo en el proceso de toma de decisiones; ii) Promover interacciones entre el gobierno y el sector privado que lleven hacia un desarrollo de políticas que apoyen el avance de cada sector; iii) Fortalecer la base de datos de conocimiento e información sobre aspectos ambientales; iv) Fortalecer la capacidad institucional y legal para implementar acuerdos internacionales sobre el medio ambiente; v) Establecer un marco de trabajo regional para la conservación de la diversidad biológica y la utilización sostenible de sus componentes; vi) Promover la protección y administración de zonas costeras y recursos marinos; vii) Promover una administración ambiental razonable de químicos tóxicos y deshechos peligrosos, y un control de traslados interfronterizos de deshechos nocivos; viii) Desarrollar un sistema para la promoción de tecnologías afines al medio ambiente; ix) Promocionar actividades regionales que fortalezcan el rol de grupos mayoritarios en el desarrollo sostenible; x) Fortalecer los mecanismos de coordinación para la implementación y administración de los programas regionales sobre medio ambiente.

\subsubsection{Políticas sociales}

\subsubsection{Marco General.}

Aunque en un principio las prioridades de ASEAN estuvieron más relacionadas con la cooperación económica y política (especialmente vinculadas con la seguridad nacional y convenios sobre el uso de energía atómica), en la década de los noventa se han diseñado políticas específicamente orientadas al área social. Entre ellas merecen especial atención - por su singularidad en el escenario internacional de cooperación regional- los tratados sobre el control y preven- 
ción del crimen transnacional (tráfico y venta de drogas, redes de corrupción y lavado de dinero, entre otros). A continuación se resumen los aspectos más significativos de esta y de otras políticas sociales ${ }^{51}$ :

\subsubsection{Medidas de política social.}

\section{Prevención y control del crimen transnacional.}

Reconociendo el crecimiento y la expansión de las actividades criminales organizadas, como el tráfico de seres humanos, la explotación transnacional de mujeres y niños, tráfico de drogas, tráfico de armas de fuego y vehículos robados, comercio ilegal de objetos culturales y recursos naturales, lavado de dinero y otras formas de crímenes financieros y corrupción, ASEAN toma la determinación y expresa su voluntad política de llevar a cabo las siguientes medidas: i) Promover la acción nacional y regional en contra del crimen transnacional y la corrupción; ii) Desarrollar estrategias efectivas orientadas a derrotar el poder económico de las organizaciones criminales, desmantelando sus alianzas y sus redes de apoyo, y desarrollar mecanismos capaces de llevar a los miembros y líderes de los grupos criminales a la justicia; iii) Mejorar el funcionamiento de las instituciones -en particular de los sistemas de justicia criminal- revisando, modemizando y armonizando apropiadamente las leyes y regulaciones existentes, para asegurar una continua eficiencia y adaptabilidad a las manifestaciones modernas del crimen organizado; iv) Establecer nuevas leyes y regulaciones, que respondan a la complejidad y sofisticación de las diversas manifestaciones del crimen transnacional, en orden a cerrar los huecos de los sistemas legales que pueden estar siendo explotados por los grupos criminales organizados; v) Fortalecer la capacidad de las instancias responsables de aplicar la ley y del personal de justicia criminal actualizando sus habilidades mediante entrenamiento especializado en el área de crimen transnacional, lavado de dinero y otros delitos económicos; vi) Intensificar la cooperación y coordinación a nivel nacional entre las agencias implicadas en el combate del crimen transnacional; y vii) Desarrollar estrechos vínculos de colaboración con organizaciones internacionales, en particular con la Interpol y ONGs relevantes.

\section{Desarrollo rural y erradicación de la pobreza.}

Con el objetivo de erradicar la pobreza, con un énfasis particular en la promoción del desarrollo de comunidades rurales progresistas, prósperas y autosuficientes, y así contribuir a la creación de una sociedad concientizada, ASEAN llevará a cabo un programa de acción compuesto por las siguientes líneas: 
a) Desarrollar la capacidad de ASEAN para monitorear y asesorar sobre la incidencia y tendencias de la pobreza. Lo que significa: i) Desarrollar un sistema común de indicadores comparativos socio-económicos que documenten la pobreza, particularmente en las áreas turales, para facilitar el desarrollo de estrategias para la reducción regional de la pobreza; ii) Fortalecer la capacidad de las agencias nacionales de estadísticas para desarrollar sistemas de administración de información para el desarrollo rural y la erradicación de la pobreza; y iii) Monitorear y asesorar el encausamiento de las preocupaciones de género en el desarrollo rural y la erradicación de la pobreza.

b) Facilitar el establecimiento de redes regionales entre los siguientes sectores: i) Organizaciones Gubernamentales relacionadas con el desarrollo rural y la erradicación de la pobreza; ii) Instituciones de desarrollo rural e investigación de la pobreza; iii) ONGs y organizaciones populares; y iv) Sectores privados y empresariales.

c) Intercambio de información, prácticas eficientes, lecciones adquiridas, capacidad investigativa y experiencia técnica relacionadas con los siguientes campos: administración de migración popular interna; micro-financiamiento y crédito rural; desarrollo de la pequeña y mediana industria; educación formal e informal; sector económico familiar y casero; transferencia de tecnologías relevantes y de alta productividad, incluyendo tecnología de la información; promoción de estudios innovadores para la educación preescolar y el cuidado infantil; promoción de iniciativas para reducir la creciente tendencia de problemas sociales; red de seguridad para grupos vulnerables y en desventaja; programas de seguridad social familiares; políticas de desarrollo rural sostenible, los cuales incluyan la protección del medio ambiente; desarrollo comunal y operación y mantenimiento de la infraestructura rural.

d) Desarrollar programas regionales de entrenamiento en las áreas prioritarias identificadas por el programa de acción.

e) Desarrollar un programa regional de voluntarios rurales.

f) Promover una mayor conciencia pública sobre la necesidad de acelerar el desarrollo rural y la erradicación de la pobreza.

Redes de seguridad social.

ASEAN reconoce que la crisis financiera y económica persiste en la región y que los problemas sociales han aumentado, ya que muchos trabajadores están desempleados y muchas comunidades vulnerables experimentan grandes dificultades y la pobreza, lo que representa una amenaza para la estabilidad regional y nacional. Es así como surge la necesidad de elaborar un Plan de Acción sobre Redes de Seguridad Social, el cual alivie las presiones sociales originadas por la crisis. El principal objetivo del Plan de Acción es desarrollar la 
capacidad de los países miembros en lo siguiente: i) Asegurar y monitorear el impacto social y económico de la crisis al identificar los grupos objetivos afectados y sus necesidades; ii) Desarrollar e implementar una red de programas de seguridad social para los más vulnerables y en desventaja; iii) Monitorear y mejorar la efectividad de la entrega de los servicios económicos y sociales; y iv) Promover la conciencia pública sobre el impacto de la crisis en los pobres.

Dentro del Plan se desarrollan cuatro políticas:

a) Asesoramiento y monitoreo del impacto social, lo cual implica la implementación de: i) Una metodología para identificar los grupos afectados por la crisis y sus necesidades; ii) Capacidad para llevar a cabo evaluaciones de impacto social para obtener información para diseñar programas de red de seguridad social; y iii) Asesoría en el micro impacto de las políticas de ajuste macroeconómico y estructural.

b) Desarrollo e implementación de programas de red de seguridad social: i) Sistemas de seguridad social para personas que trabajan en el sector informal; ii) Servicios escolares para desertores escolares y niños de la calle; iii) Workfare; iv) Programas de micro financiamiento y auto empleo; v) Servicios maternos y de salud infantil; vi) Cuidado psico-social para familias afectadas; vii) Víctimas de desastre/comunidades desplazadas; y viii) Asistencia para los de la tercera edad y los discapacitados.

c) Monitoreo y mejoramiento de las redes de servicio de seguridad social, lo cual implica desarrollar proyectos en los siguientes tópicos: i) Capacidad de las ONGs y organizaciones populares para mejorar la cobertura de los servicios de emergencia para las poblaciones afectadas; ii) Intercambio de experiencia y mejores prácticas para la efectiva entrega de los servicios de las redes de seguridad social; iii) Entrenamiento de facilitadores para llevar a cabo el desarrollo rural-comunal; y iv) Monitorear y evaluar los programas de la red de seguridad social.

d) Promoción de la conciencia pública sobre el impacto social de la crisis. Las campañas de información y motivación necesarias para apoyar los programas diseñados para lidiar con el impacto social de la crisis deberán: i) Llevar una correcta y puntual información para crear un mayor entendimiento y alentar acciones precisas entre los gobiernos de ASEAN y su sociedad civil sobre cómo tratar con el impacto de la crisis asiática; ii) Desarrollar e implementar una campaña audio-visual para ser transmitida en los países de ASEAN, promoviendo con ella la unidad de la región y la resolución de la problemática generada con el impacto de la crisis; y iii) Apuntalar la capacidad de los periodistas y los medios de ASEAN para reportar correctamente sobre la crisis, particularmente sobre su impacto en los sectores en situación de desventaja. 


\section{Desarrollo social.}

En general, las líneas a seguir por los Estados miembros de la ASEAN para asegurar un desarrollo social sostenible son: i) Actualizar los recursos humanos invirtiendo en la construcción de la capacidad institucional en entrenamiento e investigación educacional; ii) Reforzar las acciones encaminadas a mejorar la calidad de vida de las personas mediante el aseguramiento de la justicia social, la elevación de la calidad y el acceso a los servicios sociales, y trabajando por la reducción de la pobreza; iii) Compromiso con la total erradicación del analfabetismo; iv) Trabajar hacia el desarrollo de sociedades mejor informadas y educadas, a través de la cooperación en el desarrollo educativo sobre una base interdisciplinaria; v) Trabajar hacia la equitativa y efectiva participación de la mujer en todos los campos y niveles de la sociedad; vi) Complementar la cooperación regional para la supervivencia, protección y desarrollo de los niños y jóvenes; y vii) Fortalecer una respuesta colectiva a los problemas y restos que plantea la expansión del HIV/SIDA.

\section{Cooperación en cultura e información.}

Las políticas de ASEAN sobre cultura e información están enfocada a apoyar a los intelectuales, escritores, artistas y representantes de los medios de comunicación con el fin de habilitarlos para que jueguen un rol activo en el desarrollo de un sentido de identidad regional y compañerismo.

\section{Ciencia y tecnología en las políticas económicas y sociales predominan- tes a nivel mundial}

En general, las tendencias en las políticas económicas y sociales se enmarcan dentro de los requerimientos de la globalización, entendida como una intemacionalización de los procesos productivos derivados de la eliminación de las barreras a la libre circulación de las mercancías y los factores de producción. No es casual que dentro de los contenidos del TLCAN y MERCOSUR se encuentren como factor común en las políticas la reducción de las baneras al comercio.

La política científica y tecnológica frente a esta dinámica se circunscribirá, pues, a los requerimientos que surjan de la apertura al comercio internacional y a las posibilidades que se abran con la libre movilización de los factores de producción. En lo que se refiere a la política social, ésta no se encuentra claramente plasmada en los tratados. Sin embargo, es posible encontrar apartados en los cuales se hace referencia explícita a aspectos como el mejoramiento de las condiciones de vida, la educación de la mano de obra, el combate de posibles nuevas amenazas a la salud que surjan de la implementación de las nuevas políticas económicas, etc. A continuación se plantean los requerimientos de ciencia y tecnología, presentes en las políticas económicas y sociales internacionales. 


\subsection{TLCAN: Ciencia y tecnología en las políticas económicas y sociales}

Las políticas económicas y sociales que están explícitamente incluidas en el TLCAN están relacionadas principalmente con la eliminación de las barreras al comercio internacional, garantías a la libre competencia y control de las tendencias hacia el agotamiento de los recursos naturales, la protección de la salud, la regulación del transporte y la protección de la propiedad intelectual.

En el fondo, lo que estas políticas que persiguen es crear las condiciones para incrementar la participación de los países más aventajados en los campos de ciencia y tecnología. Los componentes de política del TLCAN requieren de un importante desarrollo de la ciencia y tecnología para poder obtener beneficios contemplados en el tratado. No solamente por las medidas de las que requiere el TLCAN, sino porque los niveles de desarrollo de la ciencia y tecnología entre países son demasiado dispares como para permitir que todos salgan beneficiados en la misma proporción. La productividad y competitividad de México, por ejemplo, es inferior a la de Estados Unidos hasta en el nivel de la agricultura, y la disparidad aumenta si se considera al sector industrial.

Consecuentemente, los beneficios que las empresas de México pudieran obtener no serán equivalentes a los que obtendrán las empresas de Estados Unidos, a menos que en el primero se lograran implementar innovaciones tecnológicas en áreas de producción que incrementaran la productividad. Las normas de protección de la propiedad intelectual juegan aquí un papel determinante, pues éstas pueden retrasar la utilización de tecnologías de punta.

A continuación se comentan las principales implicaciones de las medidas de política económica y social del TLCAN sobre los componentes ciencia y tecnología, aunque con la aclaración de que son apreciaciones que se derivan del documento constitutivo del TLCAN, en el cual no se trata de forma explícita la temática de la ciencia y tecnología.

\subsubsection{Políticas económicas}

Algunas de las medidas más relacionadas con la ciencia y tecnología están vinculadas la puesta en marcha de la apertura comercial y a las necesidades de protección del medio ambiente.

En lo tocante a la apertura comercial es importante mencionar que para promover la "compętencia justa" a la que hace referencia el TLCAN se necesita promover el avance científico y tecnológico, pues de otra manera los países menos desarrollados competirán condiciones de desigualdad contra países cuyo desarrollo económico se asienta en la ciencia y la tecnología. Sin embargo, la reducción de barreras al comercio implica mayor acceso a tecnología y una reducción de la necesidad de desarrollar la ciencia, pues los bienes y servicios necesarios podrían obtenerse de empresas extranjeras tecnológicamente más avanzadas. 
En la práctica, pues, la apertura comercial entraña grandes riesgos para las empresas con menor acceso a ciencia y tecnología, pues las vuelve menos productivas y competitivas en relación a empresas con mayor acceso.

En lo que atañe al medio ambiente, es importante destacar que las exigencias del TLCAN en este campo suponen el desarrollo de las ciencias naturales y sociales para definir cuáles son las implicaciones sobre el medio ambiente que deberán prevenirse. De la misma forma, suponen el desarrollo de tecnología específica para cada país, ya que, tal como establece el tratado, se requerirá de "autonomía de normas para proteger el medio ambiente y recursos naturales", pues las necesidades en este campo difieren de país a país.

En este contexto, el desarrollo de la ciencia y tecnología en el campo de la protección ambiental es totalmente necesario para que las políticas económicas de apertura comercial y, en general, de promoción de las inversiones no impacten negativamente sobre el medio ambiente y los recursos naturales. En este campo, el mismo TLCAN establece lineamientos en el sentido de que no deben disminuirse las normas de protección para atraer nuevas inversiones.

\subsubsection{Políticas sociales}

El tema social no ha recibido demasiada importancia dentro del TLCAN y solamente ha sido tratado en una forma marginal, específicamente en lo que tiene que ver con el impacto de la intensificación del comercio internacional. Los aspectos más tratados son los relacionados con la salud humana, animal y vegetal, y con la seguridad laboral.

En estos campos específicos se establecen normativas que, de forma implícita, requieren de un nivel mínimo de ciencia y tecnología. Algunas medidas de importancia están relacionadas con la vinculación entre comercio internacional y proliferación de enfermedades, plagas o, incluso, con accidentes de trabajo.

Las restricciones sanitarias y fitosanitarias requieren cierto desarrollo de la ciencia, pues se deja oportunidad para medidas más estrictas que las internacionales. Hay necesidad de evaluación de riesgo también en este campo. También de control, inspección y aprobación. Habrá comité asesor para consultas técnicas en la temática fitosanitaria Evidentemente, es importante contar con profesionales en la rama de la salud y el transporte público para diseñar las medidas de control y construcción que deberían acompañar las políticas económicas del TLCAN.

\subsection{MERCOSUR: Ciencia y tecnología en las políticas económicas y sociales}

El componente científico y tecnológico de este tratado es explícito en cuanto a los componentes, y concibe que todo el proceso de integración de mercados tiene necesariamente una dimensión científica y tecnológica. 
Incluso se cuenta con una Reunión Especializada en Ciencia y Tecnología (RECyT), cuyo objetivo principal es la "promover el desarrollo científico y tecnológico de los países miembros y de modernizar sus economías para ampliar la oferta y la calidad de los bienes y servicios disponibles, a fin de mejorar las condiciones de vida de sus habitantes". De acuerdo a documentos de la RECyT, "el énfasis está centrado en los aspectos de CyT que están más directamente relacionados con el proceso de integración económica en curso en el MERCOSUR".

Los esfuerzos por desarrollar la ciencia y tecnología en el MERCOSUR, pues, están indisolublemente ligados a las dinámicas de integración económica, la cual se concibe como un medio para mejorar las condiciones de vida. Es en este contexto que se ubican los componentes de las políticas económicas y los objetivos de la RECyT en los campos económico y social.

\subsubsection{Políticas económicas}

Un aspecto de las políticas económicas del MERCOSUR que lo diferencian del TLCAN es que, como se mencionó antes, contempla políticas de integración de políticas macroeconómicas e inclusive sectoriales entre los Estados Partes (agrícola, industrial, comercio exterior, fiscal, monetaria, cambiaria y de capitales, de servicios, aduanera, etc.). Esto lo eleva de la categoría de tratado de libre comercio a tratado de integración económica. En este marco, los objetivos generales de la RECyT persiguen principalmente una ampliación de la cantidad y calidad de la producción para tener una inserción exitosa en el proceso de globalización económica.

Los objetivos explícitos son los siguientes:

a) Aumentar la productividad de las economías del MERCOSUR;

b) Viabilizar la libre circulación de bienes, servicios y factores productivos entre los Estados Partes; y

c) Aumentar la competitividad de los segmentos productivos del MERCOSUR en terceros mercados.

Las directrices principales de la política de ciencia y tecnología son las siguientes:

a) Integración y perfeccionamiento de la infraestructura de ciencia y tecnología, sobre todo los aspectos de recursos humanos, equipamiento, organización, etc.

b) Promoción del intercambio de ideas entre investigadores, empresarios, comunicadores sociales y especialistas acerca del uso del conocimiento científico y la innovación tecnológica para alcanzar una mayor competitividad internacional. 
c) Formulación de estrategias para el mejor aprovechamiento, por parte del sector productivo, de la capacidad científica de los centros de investigación

d) Promoción de la articulación entre los diferentes sectores con intereses y posibilidades de contribuir para el desarrollo de una economía competitiva basada en la capacidad científico-tecnológica

e) Promoción de la elaboración de proyectos innovativos en el marco de la cooperación internacional con la participación de centros de investigación del MERCOSUR

f) Estímulo al papel que desempeñan los investigadores de países del MERCOSUR residentes en el exterior en la transferencia de conocimientos científicos

g) Esfuerzo de investigación y desarrollo en áreas más importantes en términos socio-económicos, seleccionando aquellas relacionadas con sectores donde se verifique una elevada complementariedad entre los países del MERCOSUR, las que permitan potencializar iniciativas de asociación entre empresas y de estas con entidades tecnológicas y también aquellas que fueran más significativas para contribuir a resolver los graves problemas de naturaleza social vivenciados en la región"52

\subsubsection{Políticas sociales}

Las políticas sociales en el tratado del MERCOSUR son explícitas y, aunque no guardan relación directa con el proceso de integración económica, sirven de fundamento para plantear la estrategia de acción del RECyT, la cual contempla la creación de un incentivo a las iniciativas en CyT relacionadas con cuestiones sociales prioritarias. En las directrices de la RECyT citadas en el apartado anterior también se contempla el tema de la relación ciencia y tecnología y la resolución de problemas sociales.

En este sentido esta resolución establece que:

"No es una cuestión productiva, directamente, que debe enfatizar las actividades de cooperación, asociación o asistencia en el MERCOSUR: temas como vivienda, tecnología educativa, salud, producción de alimentos, etc.; son posibles de ser fuerte y positivamente influenciados por acciones en Cy $\mathrm{T}^{\text {"5.3.3 }}$

Resulta claro, entonces, que las líneas que se desarrollarán en el campo de la ciencia y tecnología están relacionadas íntimamente con los principales aspectos que aborda la política social tales como educación, salud, vivienda y alimentación. Por lo demás, no queda claro si los aspectos de la previsión y seguridad social están contemplados dentro de los aspectos sociales a ser promovidos por las acciones de ciencia y tecnología. 


\subsection{Unión Europea: Ciencia y tecnología en las políticas económicas y sociales}

En los Tratados Fundadores de la Unión Europea es fácil reconocer las políticas de ciencia y tecnología en las políticas económicas y sociales. Fundamentalmente, las primeras son reconocibles en ámbitos como el desarrollo industrial, las políticas educativas, el transporte y la agricultura, entre otros. Sintéticamente, las políticas de ciencia y tecnología están orientadas a potenciar el nivel de vida de los Estados miembros y crear las condiciones necesarias para un nivel de desarrollo económico y social equilibrado entre ellos. Sin embargo, es en el Título XV, Investigación y desarrollo tecnológico, de la Tercera Parte, Políticas de la Comunidad, del Tratado Constitutivo de la Comunidad Europea, donde se plantean con mayor claridad los objetivos y modalidades de las políticas de ciencia y tecnología.

En tal Título, se afirma que la Comunidad tiene como objetivo fortalecer las bases científicas y favorecer el desarrollo de su competitividad internacional, así como fomentar todas las acciones de investigación que se consideren necesarias en virtud de las políticas sociales y económicas suscritas en el Tratado. Para este objetivo, la Comunidad estimulará en todo su territorio a las empresas, incluidas las pequeñas y medianas, a los centros de investigación y a las universidades en sus esfuerzos de investigación y de desarrollo tecnológico de alta calidad. Para la consecución de estos objetivos, la UE realizará las siguientes acciones: i) Ejecución de programas de investigación, de desarrollo tecnológico y de demostración, promoviendo la cooperación con las empresas, los centros de investigación y las universidades, y de estas entre sí; ii) Promoción de la cooperación en materia de investigación, de desarrollo tecnológico y de demostración comunitarios con los terceros países y las organizaciones internacionales; iii) Difusión y explotación de los resultados de las actividades en materia de investigación, de desarrollo tecnológico y de demostración comunitarios; y iv) Estímulo a la formación y a la movilidad de los investigadores de la Comunidad.

\subsubsection{Políticas económicas}

Para el desarrollo y cabal cumplimiento de los objetivos previstos en áreas como agricultura e industria, la Comunidad plantea la creación de redes de cooperación que se encargarán de la difusión e intercambio de conocimientos científicos y de las techologías apropiadas para el desarrollo industrial y agrícola. En lo que se refiere a la industria, la Comunidad y los Estados miembros, con vistas a acelerar la adaptación de aquélla a los cambios estructurales, favorecerá un mejor aprovechamiento del potencial industrial de las políticas de innovación, de investigación y de desarrollo tecnológico. En lo relacionado a la agricultura, se prevé, en el ámbito de la política agrícola común, una eficaz coordinación de 
los esfuerzos emprendidos en los sectores de la formación profesional, investigación y divulgación de conocimientos agronómicos, que podrá comprender proyectos o instituciones financiados en común por los Estados miembros.

Como es lógico en un marco de integración económica y social, la Comunidad Europea establece políticas específicas para el área de transportes, orientadas a establecer medidas que permitan mejorar la seguridad de los ciudadanos, así como también crear las condiciones mínimas para el transporte de mercancías (precios y regulaciones aduaneras).

Por otro lado, a fin de establecer progresivamente el mercado interior -el cual implica un espacio sin fronteras interiores, en el que la libre circulación de mercancías, personas, servicios y capitales estará garantizada- y con el objetivo de reducir las diferencias entre los niveles de desarrollo de las diversas regiones y el retraso de las regiones menos favorecidas, la Comunidad contribuirá al establecimiento $\mathrm{y}$ al desarrollo de redes transeuropeas en los sectores de las infraestructuras de transportes, de las telecomunicaciones y de la energía. En el contexto de un sistema de mercados abiertos y competitivos, la acción de la Comunidad tendrá por objetivo favorecer la interconexión e interoperabilidad de las redes nacionales, así como el acceso a dichas redes.

\subsubsection{Políticas sociales}

Como ya se ha visto, el camino hacia la adaptación a las transformaciones industriales y agrícolas se iniciará a través de la formación, la reconversión y la educación permanente a nivel profesional. Para tal meta, la Comunidad prestará su apoyo para la consolidación de redes educativas que permitan el intercambio de los recursos educativos necesarios (catedráticos, estudiantes, información tecnológica e investigaciones, entre otros) y que validen en cualquier Estado miembro los títulos académicos de los ciudadanos en formación.

\subsection{ASEAN: Ciencia y tecnología en las políticas económicas y sociales}

La cooperación de ASEAN en Ciencia y Tecnología(CyT) $)^{54}$ estará orientada a cumplir con los siguientes objetivos: i) Obtener un alto nivel de cooperación a nivel interno que sea sinergéstica, auto sostenible y con una participación activa del sector privado; ii) Diseñar una red de infraestructura relacionada con la CyT y programas para el desarrollo de los recursos humanos del sector público y privado; iii) Una transferencia tecnológica activa entre las instituciones y las industrias; iv) Incrementar el estado del conocimiento público sobre la importancia de la Ciencia y la Tecnología para el desarrollo económico de ASEAN; y v) Una cooperación extendida de Ciencia y Tecnología con la comunidad internacional. Las estrategias y acciones a seguir para la consecución de estos objetivos son: 
a) Apoyar los programas regionales de CyT que sean económica y socialmente beneficiosos para ASEAN, lo que significa: i) Identificar los usuarios finales del sector privado de los resultados de las investigaciones y buscar una participación activa de éste en el desarrollo y la investigación; ii) Apoyar el mejoramiento de los estándares, pruebas y controles de calidad de las actividades del sector privado; iii) Seleccionar y priorizar áreas de programas y proyectos que ofrecen el mayor beneficio e impacto para ASEAN como un todo; iv) Establecer un conjunto de criterios para priorizar áreas de programas y proyectos basados en factores técnicos y económicos; y v) Identificar centros de excelencia para el desarrollo de CyT.

b) Proveer una efectiva coordinación y manejo de las actividades de CyT, lo que se logrará a través de: i) Instalar un sistema de planeación, monitoreo y reporte de proyectos y programas; ii) Establecer un conjunto de objetivos para conducir el esfuerzo regional de desarrollo de la CyT; iii) Promover los vínculos estratégicos con la industria; y iv) Establecer líneas guías para la comercialización de los resultados, que incluyan compartir los derechos de propiedad intelectual y de autor.

c) Desarrollar los recursos humanos de CyT, para lo cual se realizarán las siguientes acciones: i) Desarrollar los recursos humanos de la investigación y el desarrollo para cumplir con las necesidades sectoriales; y ii) Establecer un programa de compañerismo en CyT.

d) Establecer redes de información de centros de excelencia, lo que implica: i) Desarrollar una red de información tecnológica; ii) Establecer una base de datos sobre tecnología de los grupos de negocios de ASEAN; iii) Establecer una base de datos sobre las capacidades y facilidades de ASEAN en CyT; y iv) Establecer un mecanismo de búsqueda de tecnología.

e) Promover la transferencia tecnológica entre las instituciones y la industria, las acciones para esta estrategia son: i) Establecer mecanismos para la transferencia tecnológica; y ii) Establecer un conjunto de incentivos para animar la comercialización de tecnología y la movilidad de los recursos humanos en CyT.

f) Promover la conciencia sobre CyT, para lo cual se debe: i) Reconocer las contribuciones individuales y corporativas al esfuerzo científico y tecnológico de ASEAN; y ii) Publicar una revista sobre CyT de ASEAN.

\subsubsection{Políticas económicas}

El tema de la protección de la propiedad intelectual es reconocido por ASEAN como fundamental para el desarrollo económico y la inversión de capital, en tanto que garantiza la actualización de las tecnologías de manufactura y permite un clima de confianza entre los propietarios de tecnologías. Por ello, los países 
miembros de ASEAN han firmado un Acuerdo de Marco de Trabajo para la Cooperación en Propiedad Intelectual. Entre las actividades incluidas en el Programa se encuentra: complementar y fortalecer la implementación de la propiedad intelectual; protegerla, administrarla; legislar al respecto e inculcar su respeto.

El papel de la Ciencia y la Tecnología en el sector de transportes y comunicaciones es fundamental en el proceso de integración de las economías de ASEAN. Por ello se ha creado el Plan de Acción en Transportes y Comunicaciones, el cual incluye 45 proyectos y actividades en las siguientes áreas de cooperación: transporte de múltiples maneras, interconectividad de las comunicaciones, armonización de las leyes de transporte terrestre, regulación del espacio aéreo, seguridad marítima y contaminación. Con el fin de mantener el ritmo con la creciente demanda de infraestructura y comunicaciones, los esfuerzos de la cooperación se enfocarán hacia el desarrollo de una red de transporte integrada trans-ASEAN y el manejo de los avances tecnológicos en telecomunicaciones y tecnología de la información.

En materia ambiental, ASEAN busca apuntalar la cooperación técnica y operacional través de, por un lado, el establecimiento de bases de datos sobre aspectos técnico-ambientales, en las cuales colaboren estrechamente el sector gubernamental y el privado; $y$, por otro, la promoción de tecnologías ambientales concretas.

\subsubsection{Políticas sociales}

En las políticas sociales de ASEAN tiene gran peso el componente científico y tecnológico. En lo que se refiere al desarrollo social y la eliminación de la pobreza, ASEAN hace énfasis en el desarrollo de investigaciones sobre las causas y efectos de las diversas problemáticas que aquejan a los más desposeídos (migraciones, desempleo, analfabetismo, entre otras). Así, se sugiere la elaboración de redes de información y la creación de centros de estadísticas y censos que lleven a una mejor comprensión de la pobreza y sus manifestaciones ${ }^{55}$. En este sentido, el componente científico y tecnológico está encauzado a apuntalar y potenciar el conocimiento de circunstancias sociales específicas, lo cual es visto como una condición necesaria para la resolución eficaz de las problemáticas rurales y urbanas.

En el campo de la cultura y la información ${ }^{56}$, además de que se establecen una serie de estímulos para investigaciones y trabajos sobresalientes relacionados con la cultura y el arte, se plantea utilizar la ciencia y la tecnología para: i) La difusión -por medios audiovisuales o cualquier otro que se preste para prácticas didácticas - de la cultura; ii) La preservación, conservación y promoción de la herencia cultural de ASEAN; y iii) Establecer una red de información entre las agencias de noticias y una red de transmisiones vía satélite de televi- 
sión entre los Estados miembros. En lo que se refiere al combate del crimen transnacional, el componente científico y tecnológico está enfocado a: i) Desarrollar técnicas modernas y adecuadas para la investigación y la recopilación de información para prevenir la manipulación criminal de los sistemas financieros; ii) Desarrollar estructuras tecnológicas complejas que faciliten la detección y recolección de evidencias de crímenes transnacionales (lavado de dinero, corrupción, redes de soborno, entre otros); y iii) Construir barreras para el uso y la explotación de las computadoras y la tecnología en comunicaciones con fines criminales.

Diciembre de 1998.

\section{Notas}

1. Tratado de Libre Comercio entre México, Canadá y Estados Unidos. Resumen. Comercio Exterior. No. 9, 1992.

2. Rich, P., El tratado de libre comercio de América del Norte (TLC) tres años después de entrar en vigencia. 1998, p. 3

3. Ibid. $p 6$

4. Ver Delal Baer, M., "North American Free Trade". Foreign Affairs, No. 4, 1991; Castro Martínez, P., "América del Norte. Comercio e inversiones México-Canadá: un asunto trilateral". Comercio exterior. No. 5, 1993

5. Ver CEPAL, El Tratado de Libre Comercio entre Estados Unidos, México y Canadá. Algunos aspectos relevantes. México, 1991

6. Ver Del Castillo, G., "El Tratado de Libre Comercio y las empresas manufactureras mexicanas". Comercio Extcrior, No 7, 1991

7. La fuente básica para esta exposición es The International Trade Resource and Data Exchange

8. Tratado de Libre Comercio de América del Norte. "Prcámbulo".

9. Ibid.

10. Ibid. "Objetivos y otras disposiciones"

11. Ibid. "Comercio de biencs"

12. Rich, P., Ibid. p. 5

13. Tratado de Libre Comercio de América del Norte. "Revisión de asuntos en materia de "antidumping" y cuotas compensatorias

14. Ibid. "Política en materia de competencia, monopolios y empresas del Estado"

15. Ibid. "Disposiciones sobre medio ambiente"

16. Ibid. "Mcdidas sanitarias y fitosanitarias"

17. Ibid. "Transporte terrestre"

18. Ibid. "Propiedad intelectual"

19. Ver Ferrer, A., "MERCOSUR: trayectoria, situación actual y perspectivas". Comercio exterior, No. 11, 1995

20. Ferrer, A., "El MERCOSUR: entre el consenso de Washington y la integración sustentable". Comercio exterior, No. 5, 1997, p. 354

21. Ibid.

22. Hodara, I., La articulación interna y externa de la unión aduanera del MERCOSUR.1997 
23. Tratado para la constitución de un mercado común entre la República Argentina, la República federativa del Brasil, la República del Paraguay y la República Oriental del Uruguay, 1991

24. Ibid. "Articulo 1. Propósitos, principios e instrumentos"

25. Ibid.

26. MERCOSUR, Acuerdo de alcance parcial de complementación económica, 1991

27. Tratado de Asunción

28. Ibid.

29. Ibid.

30. Ibid.

31. Cfr. Delegación de la Comunidad Europea en México, "¿Qué es la Unión Europea?", http://www.delcgacion-curopea.org

32. Tratados Fundadores de la Unión Europea (versión eninendada).

33. Un resumen descriptivo de los Tratados de Amsterdam pucde consultarse en http:// ue.eu.int/Amsterdam/cs/trcaty/main.htm

34. Ver, http://curopa.cu.int/comm/agenda2000/index_cs.htm

35. Ver, http://curopa.cu.int/curo/html/cntry.html. Tambićn "Mensaje de Coherencia", Editorial, Diario El País, España, 4 de dicicmbre de 1998.

36. Unión Europea, $A B C$ de la Unión Europea, 1998.

37. Ibid.

38. Ibid.

39. Tratados Fundadores de la Unión Europea (versión enmendada), Primcra partc, Principios.

40. El documento que se utilizará de basc para la definición de las políticas cconómicas cs Tratados Fundadores de la Unión Europea (versión enmendada), cl cual pucde scr examinado con detallc cn http://curopa.cu.int/abc/obj/trcatics/cs

41. Ver Ministerio de Relaciones Extcriores de Argentina, ASEAN, Información general: origenes, objetivos, paises que lo componen, en (http://www.cxporlar.org.ar/ intrinf.htm)

42. La gran mayoría de los textos que aquí se citan pucden ser consultados en cl sitio en internet de la ASEAN, en la dirccción (http://www.ascanscc.org)

43. Declaración de Bangkok, (http://www.ascanscc.org/history/lcader67.htm.)

44. Ver, Instituto de Estudios Latinoamcricanos, La Asociación de Naciones del Sudeste Asiático (ASEAN): Situación y perspectivas para el desarrollo de las relaciones económicas de América Latina y el Caribe con el Sudeste Asiático, (http:// lanic.utexas.cdu/ scla/docs/dsd110.htm)

45. Ver, Hirsh, M., “Ahora cs una cpidemia", Newsweck (en cspañol), vol. № 3, 21 dc cnero de 1998, pp. 34-35.

46. Instituto de Estudios Latinoamericanos, ibid.

47. Ibídem.

48. ASEAN, Economic Cooperation, (http://www.ascanscc.org/history/asn_cco2.htm)

49. Ver el texto ya citado (Economic Cooperation).

50. Ver Strategic Plan of Action on the Environment, (http://www.ascanscc.org/function/ pacnu1.htm.)

51. Las políticas sociales que a continuación se prescntan han sido tomadas de los siguientes documentos: Functional Cooperation, http://www.ascanscc.org/history/ asn_fnc2.htm; Framework for the ASEAN Plan of Action on Rural Development 
and Poverty Eradication, http:// www.aseansec.org/function/rdev_frm.htm; ASEAN Action Plan on Social Safety Nets, http://www.aseansec.org/function/pl_socsn.htm; Manila Declaration on the Prevention and Control of Transnational Crime, http:// www.aseansec.org/politics/mancrm98.htm.

52. MERCOSUR, Programa de Trabajo 1998-1999, (www.mct.gov.br/setcc/rccyt/html/ plan_trab.htm.)

53. MERCOSUR, Estrategia de acción de la RECyT, chana.mec.gub.uy/ciencia_tcch/ recyt/estrateg.htm

54. Ver, ASEAN, Plan of Action on Science and Technology, (http://www.ascanscc.org/ function/pacost1.htm)

55. Ver los literales B y C en el apartado 1.4.2

56. Ver, ASEAN, Plan of Action on Culture and Information (1994-1997), (http:/l www.aseansec.org/function/pacoci1.htm) 